NASA Technical Memorandum 88932

\title{
Toward Improved Durability in Advanced Combustors and Turbines-Progress in the Prediction of Thermomechanical Loads
}

Daniel E. Sokolowski and C. Robert Ensign

Lewis Research Center

Cleveland, Ohio

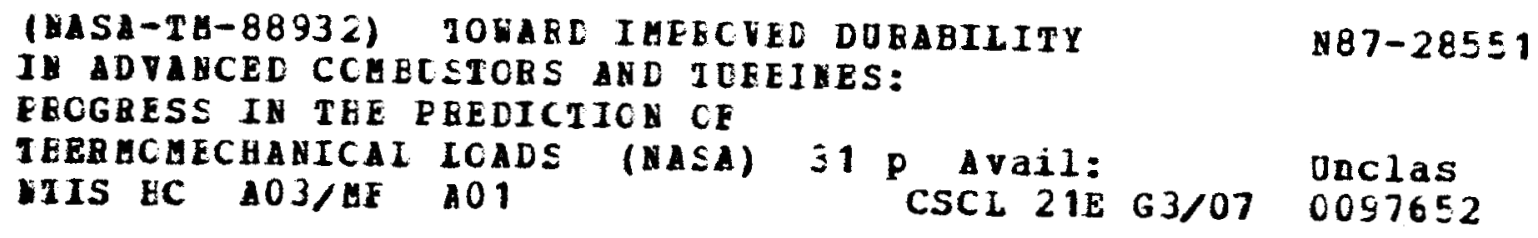

Prepared for the 31st International Gas Turbine Conference and Exhibition sponsored by the American Society of Mechanical Engineers Dusseldorf, West Germany, June 8-12, 1986 
TOWARD IMPROVED DURABILITY IN ADVANCED COMBUSTORS AND TURBINES --

PROGRESS IN THE PREOICTION OF THERMOMECHANICAL LOADS

Daniel E. Sokolowski and C. Robert Ensign

National Aeronautics and Space Administration

Lewis Research Center

Cleveland, Ohio 44135

\begin{abstract}
SUMMARY
NASA is sponsoring the Turbine Engine Hot Section Technology (HOST) Project to address the need for improved durability in advanced combustors and turbines. Analytical and experimental activities aimed at more accurate prediction of the aerothermal environment, the thermomechanical loads, the material behavior and structural responses to such loading, and life predictions for high temperature cyclic operation have been underway for several years and are showing promising results. Progress is reported in the development of advanced instrumentation and in the improvement of combustor aerothermal and turbine heat transfer models that will lead to more accurate prediction of thermomechanical loads.
\end{abstract}

\title{
INTRODUCTION
}

Since introduction of the gas turbine engine to aircraft propulsion, the quest for greater performance has resulted in a continuing upward trend in overall pressure ratio for the engine core. Associated with this trend are increasing temperatures of gases flowing from the compressor and combustor and through the turbine. For commercial aircraft engines in the foreseeable future, compressor discharge temperature will exceed $922 \mathrm{~K}\left(1200^{\circ} \mathrm{F}\right)$, while turbine inlet temperature will be approximately $1755 \mathrm{~K}\left(2700^{\circ} \mathrm{F}\right)$. Military aircraft engines will significantly exceed these values.

Since 1973 increasing fuel prices have created the demand for energy conservation and more fuel efficient aircraft engines. In response to this demand, engine manufacturers continually increased the performance of the current generation of gas turbine engines. Soon afterward, the airline industry began to experience a notable decrease in durability or useful life of critical parts in the engine hot section--the combustor and turbine. This was due primarily to cracking in the combustor liners, turbine vanes, and turbine blades. In addition, spaliing of thermal barrier coatings that protect combustor liners has occurred.

For the airlines, reduced durability for in-service engines was measured by a dramatic increase in maintenance costs, primarily for high bypass ratio engines. Higher maintenance costs were especially evident in the hot section. As shown in reference 1 , hot section maintenance costs account for almost 60 percent of the engine total.

Durability can be improved in hot section components by using a single approach or a combination of four approaches. They are the use of (1) materials having higher use temperatures, (2) more effective cooling techniques to 
reduce material temperatures, (3) advanced structural design concepts to reduce stresses, and (4) more accurate analytical models and computer codes in the design analysis process to identify hot spots, high stresses, etc.

High temperature metallic materials currently include nickel- and cobaltbased superalloys. Certain elements of these alloys, such as cobalt, are in short supply and are expensive. Recently researchers completed a study of ways to reduce their usage (ref. 2). Advanced high temperature superalloy components also include directionally solidified, single crystal, and oxidedispersion-strengthened materials. For such materials, the development time is lengthy, fabrication is sometimes difficult, and again costs are high. Thus, successful use of these materials requires a balance among design requirements, fabrication possibilities, and total costs.

Current cooling techniques tend to be sophisticated; fabrication is moderately difficult. In higher performance engines, cooling capability may be improved by increasing the amount of coolant. There is a penalty for doing this, however, in the reduction of thermodynamic cycle performance of the engine system. In addition, the coolant temperature of such advanced engines is higher than that for current in-service engines. Consequently, more effective cooling techniques are being investigated. Generally, they are more complex in design; demand new fabrication methods; and may require a multitude of small cooling holes, each of which introduces potential life-limiting high stress concentrations. Acceptable use of the advanced cooling techniques will require accurate models for design analysis.

The introduction of advanced structural design concepts usually begins with a preliminary concept that then must be proven, must be developed, and-most critically--must be far superior to entrenched standard designs. Acceptance certainly is time consuming, and benefits must be significant. For improved durability in high performance combustors, an excellent example of an advanced structural design concept is the segmented liner (ref. 3). The lifelimiting problems associated with high hoop stresses were eliminated by dividing the standard full-hoop liners into segments. At the same time, designers realized increased flexibility in the choice of advanced cooling techniques and materials, including composite ceramics.

Finally, the design analysis of hot section component parts, such as the combustor liners or turbine vanes and blades, involves the use of analytical or empirical models. Such models of ten involve computer codes for analyzing the aerothermal environment, the thermo-mechanical loads, heat transfer, and material and structural responses to such loading. When the parts are exposed to high temperature cyclic operation as in a turbine engine, the repetitive straining of the materials invariably leads to crack initiation and propagation until failure or break-away occurs. The useful life or durability of a part is usually defined as the number of mission cycles that can be accumulated before initiation of significant cracks. Thus, designers need to predict useful "life" so they can design a part to meet requirements.

Efforts to predict the life of a part generally follow the flow of analytical models portrayed in figure 1. Thus, designing of a part such as a turbine blade to meet a specified life goal may require a number of iterations through the "Life Prediction System" of figure 1, varying the blade geometry, material, or cooling effectiveness in each pass, until a satisfactory life goal is predicted. 
Present models or codes frequently predict physical behavior qualitatively but exhibit unacceptable quantitative accuracy. In general, researchers need to improve predictive capability (1) to understand and model more accurately the basic physics of the phenomena related to durability, (2) to emphasize local as well as global conditions and responses, (3) to accommodate nonlinear and inelastic behavior, and (4) to expand some models from two to three dimensions. Fortunately, these needs were identified at a time when mathematical solution techniques, computer memory, and computer computational speed were increasing dramatically. These technological advances continue.

\section{OVERVIEW OF THE HOST PROJECT}

To meet the needs for improved analytical design and life prediction tools, especially those used for high temperature cyclic operation in advanced combus-. tors and turbines, NASA is sponsoring the Turbine Engine Hot Section Technology (HOST) Project (refs. 4 to 8 ). The project was intiliated in october 1980 and presently is planned to continue through 1989.

\section{Objective}

The HOST Project will develop improved analytical models for the aerothermal environment, the thermomechanical loads, material behavior, structural response, and life prediction, along with more sophisticated computer codes, which can be used in design analyses of critical parts in advanced turbine engine combustors and turbines. More accurate analytical tools will better ensure-.during the design process-.-improved durability of future hot section engines components.

\section{Approach}

The complex durability problem in high temperature, cyclically operated turbine engine components requires the involvement of numerous research disciplines. This involvement must include not only focused research but sometimes interdisciplinary and integrated efforts.

Most disciplines in the HOST Project follow a common approach. First, phenomena related to durability are investigated, of ten using benchmark quality experiments. With known boundary conditions and proper instrumentation, these experiments result in a characterization and better understanding of such phenomena as the aerothermal environment, the material and structural behavior during thermomechanical loading, and crack initiation and propagation. Second, state-of-the-art analytical models are identified, evaluated, and then improved by more inclusive physical considerations and/or more advanced computer code development. When no state-of-the-art models exist, researchers develop new models. Finally, predictions using the improved analytical tools are validated by comparison to experimental results, especially the benchmark quality data.

\section{Programs}

Fulfillment of the HOST Project objective is being accomplished through numerous research and technology programs. Numerous activities have been 
recently completed or are in progress. HOST management has issued contracts for 39 separate activities with private industry, most of which are multi-year and multi-phased. In several activities, more than one contractor is involved because of the nature of the research and each contractor's unique qualifications. Thirteen more separate activities are being conducted through grants with universities. Finally, at the NASA Lewis Research Center, 17 major research efforts are supported by the project. Table I lists all the technical activities being conducted in the HOST Project. Because of recent changes in the project's completion date, the schedule for each activity is being revised and, consequently, is not presented in this report.

\section{RESULTS AND DISCUSSION}

Engine manufacturers interested in predicting the life of a part often use a "Life Prediction System," as portrayed in figure 1. Generally, such a system defines the engine operating requirements and characterizes the hot section environment; the system also predicts the behavior of materials and structures within that environment, especially during high temperature cyclic operation.

Development of such a system requires work involving six disciplines: instrumentation, combustion, turbine heat transfer, structural analysis, fatigue and fracture, and surface protection. HOST Project activities are organized along those discipline lines. However, this report follows the "Life Prediction System" flowchart to review progress on HOST activities. The progress report focuses on only two steps in the prediction system: characterization of the aerothermal (hot section) environment and of thermomechanical loads. The report on each activity contains three elements: the need, the product, and highlights of the technical results. References direct readers to more detail.

\section{Characterization of the Aerothermal Environment}

Within a gas turbine engine, the combustor is of primary importance to hot section durability. The life of critical hot section parts, such as the combustor liners and turbine blades and vanes, is affected by the temperature level and uniformity of gases flowing over their surfaces.

The gas temperature level is established by the engine performance requirements. Generally, higher performance in commercial aircraft engines is obtained by increasing the overall pressure ratio and the component efficiency. One result of increased pressure ratio is a proportionate increase in compressor discharge air temperature. Since part of the compressor air is used for combustor liner and turbine airfoil cooling, the impact is higher coolant temperatures. Military aircraft engines obtain higher performance primarily by burning more fuel and thereby increasing the combustor temperature rise. The impact is not only a greater thermal load on the liners but also a higher average turbine inlet temperature.

Obtaining gas temperature uniformity is particularly challenging where complex aerodynamics, chemical kinetics, and turbulent heat transfer take place. The combustor must accept a range of characteristics in airflow delivered to it by the compressor. Compressor discharge air, for instance, can exhibit different flow velocity radial profiles as the engine power setting is 
changed and as the engine ages. This can affect the flow splits for combustion air and for shroud air, which is used for dilution and liner cooling. Nonuniform compressor alrflow circumferentlally can impact liner backside temperatures and cause liner temperature axial streaking. It also has been known to affect combustor exit temperature profiles and pattern factor, which directly influence thermal loading proflles on turbine first stage vanes and blades.

Finally, the combustion system must accept a range in the quality of fuels to be burned. In recent times, the aromatic content of aircraft gas turbine fuels has not only increased but varies from one location to another in the world. The most notable effect of lower quality fuel is in coke formation. If the coke build-up occurs on the fuel injector, the change in spray pattern may be sufficient to cause temperature streaking on the liners. Coke deposits on the injectors or liners may reach a certain size, break away, and flow into the turbine where they cause "shot-peening" of airfoll surfaces-some of which may have thermal barrier coatings-... or become trapped between a rotating blade and turbine case, with subsequent damage to the seal. Another effect of higher aromatic fuels is an increase in radiant heat loading on hot section parts that "see" such radiation.

With the above considerations in mind, it is of utmost importance to characterize and understand the aerothermal environment around hot section parts. This is the initial step in developing more accurate models to analytically predict such phenomena. Such characterization is provided by appropriate advanced instrumentation that is used in carefully designed and conducted experiments. To this end, several activities supported by the HOST Project were undertaken and have now been completed. Such activities under the instrumentation discipline allow one to view the interior of an operating combustion chamber, to measure high frequency gas temperature fluctuations, and to measure instantaneous and average gas flow velocities. Under the combustion discipline, a broad data base has been obtained for dilution jet mixing and has been used to develop empirical relations that allow designers to predict combustor exit temperature profiles. In addition, state-of-the-art aerothermal models of the combustion system have been assessed and recommendations made for required improvements. Summaries of activities that have improved the researcher's or designer's ability to characterize the aerothermal environment are presented below.

Hot section viewing system. - Development of a diagnostic tool to look inside an operating turbine engine hot section component is important for detecting abnormal operation and fallure modes. For example, looking inside a combustor will help determine the location and shape of the flame and the operating conditions under which the flame impinges on the combustor wall or liner. The condition of the liner(s), fuel injectors, bulkhead, and turbine inlet guide vanes could be qualitatively assessed during combustor operation. observed hot spots can be monitored for progressive liner damage, including crack initiation and propagation. It also may be possible to observe the accumulation of coke deposits and fuel spray pattern and to measure relative or absolute flame temperatures. Flame instability and turbulence could be observed and/or measured and possibly related to combustor acoustic noise.

The purpose for this activity, which was conducted by United Technologies Research Center (UTRC), was to develop an optical system for viewing the interior of a combustor (or perhaps turbine) during high pressure, high temperature operation and to explore methods for improving the information content of 
recorded images. The final system was planned for use inhouse at NASA Lewis as a research tool and for loan to qualified users.

The completed viewing system consists of a water-cooled probe, a probe actuator, controls, an optics/light source interface, and interchangeable viewing optics. The interchangeable viewing optics provide a variety of field-ofview and resolution options. Figure 2 is a schematic of the viewing system, while figure 3 shows the probe.

Development of the system has included testing of a pulsed laser fllumination source and computer image enhancement. Following delivery of the system to NASA Lewis, it has been used in the High Pressure Facility to obtain high speed movies of burning around fuel injectors. Using the results of this research, UTRC is constructing several more probes for its own corporate use, as well as for an electric power company to use on a gas turbine generating system. The U.S. Navy soon will be using the NASA viewing system in a combustor test rig. Reference 9 provides more detailed information on this viewing system.

Researchers believe that future testing with the system using pulsed laser illumination, coupled with a suitable filter and a short duration shutter that allows suppression of the intense flame fllumination, will provide a "view" through a luminous flame. Image enhancement then can be used to expand the range of contrast of images that have been recorded.

Dynamic gas temperature measurement system. - In gas turbine engines, it is generally accepted that large scale gas temperature and velocity fluctuations occur throughout the combustion chamber and in the combustor exhaust gases because of incomplete mixing of the combustion gases and air used for dilution and liner cooling. The fluctuating temperatures and velocities of these exhaust gases have been related to damage to turbine vanes and blades. That is, temperature variations in the gas stream cause measurable temperature variations on the surface of such parts. Thus, a probe that can accurately measure the amplitude and frequency of the gas stream temperature fluctuations is necessary in order to improve the prediction of turbine blade and vane life. In addition, the understanding of turbulent combustion requires a knowledge of the temperature variation with time.

In the past, high-response measurements have been attempted by using a passive electrical compensation network based on an estimate of the temperature probe time constant. The intent of an effort performed by Pratt and Whitney was to develop a more rigorous method for measuring gas temperature fluctuations at frequencies up to $1000 \mathrm{~Hz}$ with peak temperatures of up to $1922 \mathrm{~K}$ $\left(3000^{\circ} \mathrm{F}\right)$ and a temperature fluctuation range of up to $\pm 755^{\circ}\left(1360^{\circ} \mathrm{F}\right)$. The system had to be capable of measurements in a combustor exhaust at pressures up to 20 atmospheres.

The approach chosen for development is shown in figure 4 . It features a two element thermocouple probe. A compensation function is derived using the two-thermocouple signal amplitude ratio in response to the gas temperature fluctuation. Frequency compensation for the recorded signals can then be accomplished for high frequency fluctuations up to a limit imposed by signalto-noise ratio. 
The measurement and compensation system have been developed and evaluated in equipment ranging from laboratory burners to full-size commercial and military engines. Test results with the probe located at the exit plane of an atmospheric combustor are presented in figure 5, while similar results using a F-100 engine combustor are presented in figure 6. In each figure, the instantaneous temperature versus time is shown: first, for the uncompensated thermocouple output and, second, for the compensated thermocouple output. The dynamic temperature range for the compensated output not only shows the importance of compensation but also the significant fluctuations in temperature levels on the order of $\pm 755 \mathrm{~K}\left(1360^{\circ} \mathrm{F}\right)$ occurring in a turbine engine combustor. See reference 10 for detalls on the probe concept selection, development, and testing.

Further efforts in progress are (1) experimentally verifying the accuracy of the probe using a specially designed rig to produce known temperature fluctuations, (2) reducing the time for data processing, and (3) reprogramming the compensation system to run on a general purpose computer.

Laser anemometry for hot section applications. - The gases flowing through a turbine engine hot section exhibit complex behavior, including turbulence. In the turbine component with its successive stages of flow turning vanes and rotating blades, the behavior is difficult to characterize, let alone model, for performance and heat transfer. Understanding of such flow behavior requires a detailed knowledge of the flow stream velocity components in the axial, circumferential, and radial directions. Such information is needed within the vane passages, between vanes and blades, and within the blade passages; it must also include secondary flows over the tips of the blades. To understand the flow behavior and to measure flow velocity components, researchers at the NASA Lewis Research Center used the following approach: 1) conduct experiments of increasing complexity from a single bench type to possibly real engine rigs and 2) develop a nonintrusive measuring probe that will not be damaged by the hostile environment, will not change the flow behavfor being measured, and will provide measurements within rotating blade passages. The only means to do this is with a laser anemometer system. Such a system has been developed; it currently measures a single velocity component in these hostile environments.

The primary optical design for the laser anemometer is a conventional single component dual-beam, fringe-type configuration, as illustrated in figure $7(a)$. System components include the optics, a traversing stage for three-coordinate positioning of the system relative to the test rig, a particle generator for seeding the gas stream with $1.0 \mathrm{\mu m}$ alumina, and fused silica windows machined to match the inside curvature of the turbine case. All components of the system, including a minicomputer for traverse control and data acquisition, have been developed and tested in an atmospheric jet combustor facility. Figure $7(b)$ shows the laser anemometer system adjacent to the combustor rig. An identical system is being installed in the Warm Turbine Rig at Lewis. Test measurements will provide data for mean velocity, flow angle, turbulence intensity, and turbulence scale. A further discussion of the system development and preliminary test results may be found in references 5 and 6 . Analytical efforts performed during optimization of the laser anemometer system are reported in reference 11 .

Combustor aerothermal modeling. - To enable the design of a combustor that alleviates high temperature gradients and produces a desired exit temperature 
distribution, researchers must develop a thorough and accurate characterization and understanding of the convective and radiative heat fluxes in the combustor. This is the driver for the combustor aerothermal modeling program.

The objectives of this three phase program are: first, identify state-ofthe-art combustor aerothermal models, assess their predictive capability, and recommend improvements; second, develop beneficial improvements to the aerodynamic aspects of the more promising models; and finally, incorporate chemical reactions into the models that will then allow local heat flux and temperature predictions.

The first phase of the effort, model assessment, was completed by Garrett Turbine Engine Company, Pratt and Whitney, and General Electric Company and is reported in references 12 to 14 , respectively. In brief, current models can qualitatively predict the complex three-dimensional flow field within a combustor. Quantitative modeling of these flows, however, requires the reduction of both computer execution times and removal of numerical diffusion in the calculations. Researchers believe that as more efficient numerical solutions are developed, effective investigations will be possible in areas such as modeling of turbulence and scalar transport in the interaction of various flow streams and the development of the fuel spray and its interaction with the surrounding airstream. Finally, the assessment efforts discovered a serious deficiency of available and suitable benchmark quality experiments.

Based on findings and recommendations of the first phase effort, the second phase efforts, currently in progress, are necessartly focused on improving analytical models and computer codes. Important benchmark quality experiments also are being conducted to aid model development and validation. The activities include efforts to improve numerics, flow interaction experiments, and fuel swirl characterization experiments. Allison Gas Turbine Division is involved in all three general areas, while AvCO-Everett, United Technologies Research Center, and the University of Minnesota are each addressing a specific area. Additional efforts at Purdue University and the University of California at Irvine directly support the effort at Allison. Table I indicates the contract or grant number associated with each contractor/grantee and the work being addressed.

Dilution fet mixing studies. - Mixing combustion gases with cooler dilution air inside the combustor is important not only to reduce the bulk temperature level of gases flowing into the turbine but also to provide acceptable circumferential and radial temperature profiles at the combustor exit. Since these profiles determine the local thermal loads on turbine first stage vanes and blades, they directly influence durability and cooling requirements of such parts. Previous NASA-sponsored efforts dealt primarily with obtaining experimental data and developing empirical correlations for a single row of jets mixing with an isothermal normal flow in a constant cross-sectional area duct. A more inclusive data base was needed to develop such correlations further and improve temperature prediction accuracy for combustors.

The purpose for this activity, which was conducted by the Garrett Turbine Engine Company, is twofold. First, extend the data base for jet mixing to include realistic effects of combustion chamber (1) flow area convergence, (2) nonisothermal mainstream flow, (3) opposed (two-sided) in-line and staggered injection, (4) orifice geometry, and (5) double (axial) rows of holes. Second, 
extend empirical correlations. An interactive computer code is under development at NASA Lewis for mixing analyses and three-dimensional pictorial representation of the temperature field at the combustor exit.

A schematic of the test section and orifice configurations is shown in figure 8. Tests were conducted using heated air for the mainstream, which ranged from $477 \mathrm{~K}\left(400^{\circ} \mathrm{F}\right)$ to $811 \mathrm{~K}\left(1000^{\circ} \mathrm{F}\right)$, and normally injected air jets having a nominal value of $294 \mathrm{~K}\left(70^{\circ} \mathrm{F}\right)$. Changes in temperature distribution at the test section exit due to varlations in mixing were noted primarily as a function of jet-to-mainstream momentum flux ratio, orifice characteristics, and spacing.

An example of a typical dilution jet flowfield is shown in figure 9 with a pictorial representation of the temperature profiles shown for experimental data and empirical model predictions. Several publications that cover the three work phases are indicated by references 15 to 17 , respectively. Results of velocity measurements and correlations, along with temperatures and velocities calculated using a three-dimensional numerical code, are forthcoming in a report under contract NAS3-221!0.

The experimental data and empirical model developed in this program have been put into use by engine manufacturers as a design tool. The usefulness of an empirical model outside the measurement range, however, is uncertain at best. The applicability of these empirical models is limited to the geometry and flow conditions and to parameters that have been correlated. Numerical models do not have these limitations, and for more generic applications a three-dimensional numerical model will be needed as a predictive tool. Current numerical results compared with the experiments are very promising (see fig. 9) and indicate that they can be used now in their present form as a diagnostic tool for establishing flow trends. The numerical model correctly describes the effects of the principal flow and geometric variables.

\section{Characterization of the Thermomechanical Loads}

Following the characterization of the aerothermal environment, the next important step in hot section analyses is the characterization and understanding of thermal and mechanical loads imposed on the part (see fig. 1). HOST Project activities in this area range from advanced instrumentation measuring heat flux, to extensive heat transfer experiments, and to improvements of models and computer codes. In the HOST Project emphasis has been on aerothermal loads. A number of these activities are discussed below.

Turbine heat flux sensors. - For air cooled turbine blades and vanes, a critical design parameter is the hot side heat transfer coefficient. Current techniques for estimating this coefficient do not provide the accuracy needed to predict actual airfoil temperatures. To provide more accurate heat transfer coefficlent values, researchers must know the heat flux to an airfoil surface, plus the flow stream and surface temperatures. Very little data is avallable on heat flux in realistic gas turbine environments. Researchers know that convective heat transfer is predominant at lower turbine pressures and temperatures. But as turbine engine pressure and temperatures are increased for performance gains, along with the possibility of burning more luminous broadened specification fuels, scientists believe that radiation heat transfer is 
of greater importance. Thus, development of a sensor that accurately measures total heat flux is important.

The objectives of this work are, first, to develop and test total heat flux sensors that are suitable for use on turbine airfoils and, second, to compare several methods of measuring heat flux in an atmospheric combustor rig.

The effort, which was conducted by Pratt and Whitney (P\&W), built on the experience gained in a pre-HOST program that developed total heat flux sensors for use in combustor liners (see ref. 18). For airfoils, two sensor designs were identified as meeting the following criteria: sensors must be compatible with blade and vane materials (nickeland cobalt-based alloys), must have good spatial resolution (sensing diameter less than $0.15 \mathrm{~cm}$ or $0.06 \mathrm{in.}$ ), must not interfere significantly with local temperature distribution and heat flow, and must not change the aerodynamics of the airfoils. The sensors meeting these criteria were the embedded thermocouple design (fig. $10(a)$ ) and the Gardon gage design (fig. $10(b)$ ).

Development of the blade and vane heat flux sensors has been completed and reported in reference 19. Experimental work to compare these sensors with other heat flux measuring techniques has been completed recently and will be reported under contract NAS3-23529. Results from this work indicate that these sensors are sensitive to transverse temperature or heat flux gradients. Further work to investigate this sensivity and to devise ways to minimize it is planned. In addition, demonstration tests of combustor liner total heat flux sensors have been reported in reference 20 . This work compares measurements made with a total heat flux sensor and a commercial optical radiometer. Typical results from two types of heat flux sensors are presented in figure 11 .

Turbine airfoll external heat transfer. - The trend toward higher turbine inlet temperatures to achieve advanced turbine engine performance imposes a more severe thermal load on turbine airfoils--that is, the nozzle guide vanes and rotating blades. At the same time, lack of the ability to predict local gas-to-airfoil heat transfer rates with acceptable accuracy is a principal obstacle toward timely and cost-effective development of high temperature turbine hardware. Improvements in predictive capability in this area can have broad and significant benefits in terms of enhanced turbine life, reduced development and maintenance costs, and improved engine performance.

All modern high pressure turbine airfolls contain complex cooling techniques. It is convenient to separate these techniques into those that become part of the external flow field (i.e., fllm cooling) and those that do not. Two efforts have been completed recently that experimentally and analytically address the needs of both types of airfoll cooling. In each effort, the objectives included these: (1) assess the capability of currently available modeling techniques for predicting airfoll surface heat transfer distributions in a two-dimensional flow field, (2) acquire experimental data as required for model improvement and validation, and (3) further develop analytical methods.

The first effort, which is reported in detail in reference 21 , focused on the external surface heat transfer of a convectively cooled airfoil. A broad data base covering a wide range of airfoll profiles and operating conditions was provided by two sources. Three data sets were selected from the literature. Two additional airfoils (identified as C $3 X$ and Mark II), representative of highly loaded, low solidity airfoils, were tested in a three vane cascade 
at simulated engine conditions. The two airfoil profiles tested are shown in figure 12 .

The analytical activity was conducted because there is no standard for consistently and accurately predicting external convective heat transfer to solid surface airfolls operating in a gas turbine environment. To better ensure early and wide user acceptance of any improvements in predictive capabilities, the initial task in this activity involved identifying and assessing the current state-of-the-art predictive methods. Three boundary layer methods were selected. The major differences among the methods were in the analytical form of the governing equations that were solved and the complexity of the turbulence model assumed. After documenting the inadequacies of the methods over the broad range of airfoll profiles and operating conditions, researchers channeled further examinations and development into one promising method. This is the differential boundary layer method, avaliable in the computer code STAN5 (ref. 22), which uses a mixing length hypothesis (MLH) or zero-equation turbulence model formulation. To better predict airfoll heat transfer, scientists further developed the turbulence model in STAN5. Details of this development and the resulting modified STAN5 code are presented in reference 21 . To illustrate the improved prediction capability, figure 13 presents a comparison of the $C 3 X$ airfoil experimental heat transfer coefficient data with the unmodified and modified STAN5 predictions.

A second effort, involving leading edge film cooled airfoils, addresses durability requirements in some advanced turbine engines. It has been demonstrated that multiple hole (i.e., shower head) film cooling of the critical leading edge region can significantly improve durability for airfoils that otherwise are cooled internally by a combination of convection and jet impingment techniques. Minimal systematic effort has been directed at characterizing local heat transfer downstream of leading edge injection for highly loaded airfoll surfaces operating at realistic levels of Mach number, Reynolds number, and wal1-to-gas and coolant-to-gas temperature ratios.

Researchers have completed the second effort and reported on it in detail in reference 23 . These researchers extended the initial data base by using the same two-dimensional linear cascade and $C 3 X$ airfoil profile, having a leading edge showerhead array consisting of five rows of cooling holes fed by a common plenum. The film cooled airfoll is shown in figure 14, along with the convectively cooled design for comparison. Recovery region heat transfer measurements were taken at two transonic exit Mach number conditions with true chord Reynolds numbers of order $10^{6}$. In addition, both blowing strength and coolant temperature were varied to quantify jet turbulence production and thermal dilution mechanisms.

The researchers then used the extended data base to guide development of a mathematical model for describing the highly complex, three-dimensional, coolant jet/mainstream flow interaction process in terms of a two-dimensional boundary layer analysis framework. The objective was to create a method for predicting recovery region external convective heat transfer phenomena associated with a leading edge film cooling process. The method developed is, indeed, a direct extension of a nonfilm cooled two-dimensional boundary layer analysis formulation that is reported in detall in reference 23 . In brief, two parameters (FTU for free-stream turbulence intensity factor and FTG for freestream total gas temperature factor) are defined to model turbulence production and thermal dilution phenomena. Computationally, these two parameters are used 
to alter the boundary layer outer edge free-stream turbulence intensity and total gas temperature (enthalpy) boundary conditions. A comparison of results from model prediction and experimental data is presented in figure 15 .

Finally, as computer technology evolves, boundary layer analys is design procedures are likely to be replaced by Reynolds and/or full Navier-Stokes $(\mathrm{N}-\mathrm{S})$ equation analyses. Currently, the $\mathrm{N}-\mathrm{S}$ framework is not an industry standard. Its continued development, however, will improve future capability and reduce empiricism. In some areas, as shown above, this is an absolute necessity. To this end, a $\mathrm{N}-\mathrm{S}$ method development program is being supported by the HOST Project. The status of this analytical effort to apply timedependent ensemble-averaged Navier-Stokes equations to transonic turbine cascade flow fields is reported in references 7 and 24 . Results to date indicate the ability of the $\mathrm{N}-\mathrm{S}$ analysis to predict, in reasonable amounts of computation time, the surface pressure distribution, heat transfer rates, and viscous flow development for turbine cascades operating at realistic flow conditions. This code's ablilty to predict the c3X data is shown in figure 16. The fact that the code seems to be picking the chordwise fluctuations in the data is particularly encouraging.

Three-dimensional boundary layer code assessment. - It is widely recognized that turbomachinery flows are three-dimensional. Two-dimensional boundary layer methods, such as STAN5, are at best only applicable to midspan regions, such as described above. Some important insight into threedimensional effects can be gained by the use of three-dimensional boundary layer analyses. As part of the HOST Project, an effort was directed toward the assessment, improvement, and documentation of the three-dimensional boundary layer code described in reference 25. A particular problem with threedimensional boundary layer analyses is the definition of the boundary conditions. They, too, are frequently three-dimensional. The work described in reference 25 paid particular attention to this problem and developed some generalized techniques for defining the boundary or edge conditions.

The results of the assessment of a three-dimensional boundary layer analysis are demonstrated in figure 17, which compares experiment and analysis for end-wall heat transfer. The results show both the strength and the weakness of a three-dimensional boundary layer analysis. Qualitatively the agreement is good. The overall levels compare quite well, and the Stanton number contours in the tralling edge region show very simflar trends. In the leading edge region near the so-called saddle point, however, the experimental Stanton number contours are not captured by the analysis. This is the region where the horseshoe vortex is formed that has been shown to have a strong heat transfer effect. The horseshoe vortex cannot be represented in this boundary layer analysis.

Gas-side heat transfer with rotation. - All of the turbine heat transfer work described so far was conducted in the stationary frame of reference. Rotation, of course, is an important variable in turbines. Accordingly, the project includes several efforts conducted in the rotating frame of reference. These efforts are just beginning to produce results. For now the program can be described, but only a qualitative preview of the results can be presented.

One effort continues to focus on the external flow over the turbine airfolls. The work is being done in a large low speed turbine that has already 
been used to obtain a significant body of turbine data, as for example rotorstator interactions described in reference 26 . The data being acquired includes heat transfer coefficients along the midspan of the pressure and suction surfaces on the vanes and the rotating blades. Both high and low inlet turbulence are being studied. The rig is to be configured as both a single stage, shown in figure 18, and a one and one-half stage turbine. The singlestage data are complete. The turbulence effects are quite significant on the first vane. The overall heat transfer is highest on the blades, but for the most part the effect of turbulence is submerged in the vane wake effects. Although rotational forces exist on the external airfoll surfaces in a rotating machine, they are not thought to be large. The vane wake effects are much greater.

Coolant-side heat transfer with rotation. - The findings above with gas side heat transfer do not apply to the internal coolant passages. Here buoyancy and Coriolis forces are expected to be quite strong. In addition the passages themselves are very complex. This complexity is lllustrated in figure 19. The serpentine passages with turbulators on the surfaces are being simulated in an experiment that rotates a test section with outflow, inflow, and back out again. Both smooth and turbulated surfaces are being studied. The turbulators are at $90^{\circ}$ and $45^{\circ}$ to the flow. Researchers are using dimensional analysis on the data. The smooth wall data are also being compared to computations using the TEACH code (ref. 27), which has been modified to include rotational terms. The smooth wall experiments are complete. The trends in the data are shown in figure 20 . The pronounced effect of rotation is obvious. Early indications suggest this data set can be successfully correlated by appropriate nondimensional groupings of buoyancy and rotational parameters. Further information on this activity can be found in references 5 to 7 .

\section{CONCLUDING REMARKS}

In this paper, progress has been reported on 16 of the 69 research activities that have been initiated and supported by the HOST Project. The focus has been on more accurate prediction of the aerothermal environment and thermal loads. Progress in the remaining efforts is also being made, especially for activities related to more accurate prediction of material behavior, structural response, and life prediction.

The cooperative efforts among contractors, academia, and government connected with the HOST Project have been outstanding. While the project justification was based on civil aircraft propulsion needs, the technical results will have both civil and military applications.

For the improved or new analytical models and codes that are being developed in the HOST Project, experimental validation is limited primarily to the benchmark quality data. The burden is on the user community to further validate the HOST products, where required, with real engine-like data and, in turn, to develop confidence for broader usage of the models and codes.

During the past year, a national policy statement was made by G.A. Keyworth, II (ref. 28) that addresses specific goals for the United States in three areas--subsonics, supersonics, and transatmospherics. With propulsion as the pacing technology to achieve these goals, it seems certain that the trends toward increasing hot section pressure and temperatures will continue. 
The higher temperatures will continue to challenge the durability requirements of advanced combustors and turbines and perhaps even higher pressure ratio compressors. In the future, nonmetallic high temperature materials, such as polymer matrix composites, ceramic matrix composites, and monolithic ceramics, will eventually be introduced to hot section applications. Successful and costeffective applications of such materials will require specific analytical models--for which few exist. However, they may evolve from the current models and codes in the HOST Project. Finally, revolutionary structural design concepts may be required, primarily for application of the nonmetallic materials. To ensure early success in such applications, generic models and codes will be required for design analyses.

\section{REFERENCES}

1. Dennis, A.J., and Cruse, T.A., "Cost Benefits from Improved Hot Section Life Prediction Technology," AIAA Paper 79-1154, June 1979.

2. Stephans, J.R., "COSAM Program Overview," COSAM (Conservation of Strategic Aerospace Materials) Program Overview, NASA TM-83006, 1982, pp. 1-11.

3. Tanrikut, S., Marshall, R.L., and Sokolowski, D.E., "Improved Combustor Durability - Segmented Approach with Advanced Cooling Techniques," AIAA Paper 81-1354, July 1981.

4. Turbine Engine Hot Section Technology (HOST), NASA TM-83022, 1982.

5. Turbine Engine Hot Section Technology (HOST), NASA CP-2289, 1983.

6. Turbine Engine Hot Section Technology (HOST), NASA CP-2339, 1984.

7. Turbine Engine Hot Section Technology 1985, NASA CP-2405, 1985.

8. Sokolowski, D., and Ensign, C., "Improved Durability in Advanced Combustors and Turbines through Enhanced Analytical Design Capability," AIAA Paper $85-1417$, July 1985.

9. Morey, W.W., "Hot Section Viewing System," R84-925830-33, United Technologies Research Corp., East Hartford, CT, 1984. (NASA CR-174773)

10. Elmore, D.L., Robinson, W.W., and Watkins, W.B., "Dynamic Gas Temperature Measurement System," PWA/GPD.FR-17145-VOL-1, Pratt and Whitney Aircraft, West Paim Beach, FL, 1983. (NASA CR-168267)

11. Seasholtz, R.G., Oberle, L.G., and Weikle, D.H., "Optimization of FringeType Laser Anemometers for Turbine Engine Component Testing," AIAA Paper 84-1459, June 1984.

12. Srinivasan, R., et al., "Aerothermal Modeling Program, Phase I," GARRETT21-4742-1;-2, Garrett Turbine Engine Co., Phoenix, AZ, 1983. (NASA

CR-168243-VOL-1;-VOL-2)

13. Sturgess, G.J., "Aerothermal Modeling Program - Phase I," [WA-5907-19, Pratt and Whitney Aircraft, East Hartford, CT, 1983. (NASA CR-168202) 
14. Kenworthy, M.J., Correa, S.M., and Burrus, D.L., "Aerothermal Modeling, Phase I," 1983. (NASA CR-168296-VOL-1,-VOL-2)

15. Srinivasan, R., Berenfeld, A., and Mongia, H.C., "Dilution Jet Mixing Program - Phase 1," GARRETT-21-4302, Garrett Turbine Engine Co., Phoenix, $A Z, 1982$. (NASA CR-168031)

16. Srinivasan, R., Coleman, E., and Johnson, K., "Dilution Jet Mixing Program," GARRETT-21-4804, Garrett Turbine Engine Co., Phoenix, AZ, 1984. (NASA CR-174624)

17. Srinivasan, R., Coleman, E., Meyers, G., and White, C., "Dilution Jet Mixing Program," GARRETT-21-5418, Garrett Turbine Engine Co., Phoenix, AZ, 1985. (NASA CR-174884)

18. Atkinson, W.H., and Strange, R.R., "Development of Advanced HighTemperature Heat Flux Sensors," PWA-5723-27, Pratt and Whitney Aircraft, East Hartford, CT, 1982. (NASA CR-165618)

19. Atkinson, W.H., Cyr, M.A., and Strange, R.R., "Turbine Blade and Vane Heat Flux Sensor Development Phase I," PWA-5914-21, Pratt and Whitney Aircraft, East Hartford, CT, 1984. (NASA CR-168297)

20. Atkinson, W.H., Cyr, M.A., and Strange, R.R., "Development of Advanced High Temperature Heat Flux Sensors, Phase II," PWA-5914-39, Pratt and Whitney Aircraft, East Hartford, CT, 1985. (NASA CR-174973)

21. Hylton, L.D., et al., "Analytical and Experimental Evaluation of the Heat Transfer Distribution Over the Surface of Turbine Vanes," EDR-11209, Detroit Diesel Allison, Indianapolis, IN, 1983. (NASA CR-168015)

22. Crawford, M.E., and Kays, W.M., "STAN5 - A Program for Numerical Computation of Two-Dimensional Internal and External Boundary Layer Flows," NASA CR-2742, 1976.

23. Turner, E., Wilson, M., Hylton, L., and Kaufman, R., "Turbine Vane External Heat Transfer. Volume I-Analytical and Experimental Evaluation of Surface Heat Transfer Distributions with Leading Edge Showerhead Film Cooling," EDR-11984-VOL-1, Detroit Diesel Allison, Indianapolis, IN, 1985. (NASA CR-174827)

24. Yang, R.J., et al., "Turbine Vane External Heat Transfer. Volume IINumerical Solutions of the Navier-Stokes Equations for Two- and ThreeDimensional Turbine Cascades with Heat Transfer," EOR-11984-VOL-2, Detroit Diesel Allison, Indianapolis, IN, 1985. (NASA CR-174828)

25. Anderson, 0.L., "Assessment of a 3-D Boundary Layer Analys is to Predict Heat Transfer and Flow Field in a Turbine Passage," R85-956834, United Technologies Research Center, East Hartford, CT, 1985. (NASA CR-174894)

26. Dring, R.P., Josiyn, H.D., Hardin, L.W. and Wagner, J.H., "Turbine RotorStator Interaction," Journal of Engineering for Power, Vol. 104, No. 4, Oct. 1982, pp. 729-742. 
27. Patankar, S.V. and Spaulding, D.B., "A Calculation Procedure for Heat, Mass and Momentum Transfer in Three-Dimensional Parabolic Flows," International Journal of Heat and Mass Transfer, Vol. 15, No. 10, Oct. 1972, pp. 1787-1806.

28. Keyworth, II, G.A., "National Aeronautical R\&D Goals, Technology for America's Futures," Executive Office of the President, Office of Science and Technology Policy, Washington, D.C., Mar. 1985. (PB86-209772) 
Ins trumentation

*Hot Section Viewing System

*Dynamic Gas Temperature Measurement System $-\dot{A} \ldots \ldots \ldots \ldots$

* Dynamic Gas Temperature Measurement System - B $\ldots \ldots \ldots \ldots \ldots$

Turbine Static Strain Gage $-A \ldots \ldots \ldots$

Turbine Static Strain Gage - B $\ldots \ldots \ldots \ldots \ldots$

*Turbine Heat Flux Sensors ....................

Laser Speckle Strain Measurement ${ }_{\text {High Temperature Strain Gage Materiais } \ldots \ldots \ldots} \ldots \ldots$

Hot Sectionature Strai

* Laser Anemometry for Hot Section Appications $\ldots \ldots \ldots$

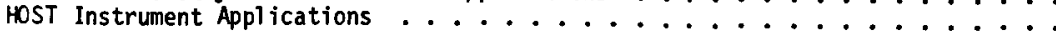

Combustion

*Assessment of Combustor Aerothermal Models - I

*Assessment of Combustor Aerothermal Models - II $\ldots \ldots \ldots$

*Assessment of Combustor Aerothermal Models - III $\ldots \ldots \ldots \ldots \ldots$

Improved Numerical Methods - I . . . . . . . . . . . .

Improved Numerical Methods - III $\ldots \ldots \ldots$

Flow Interaction Experiment $\ldots \ldots \ldots \ldots$

Fuel Swirl Characterization $-\mathrm{I} \ldots \ldots \ldots \ldots \ldots \ldots$

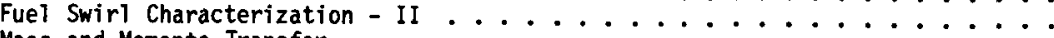

Mass and Momenta Transfer

Diffuser/Combustor Interaction

*Dilution Jet Mixing Studies . . . . . . . . . . .

Lateral Jet Injection into Typical combustor Fiowfieids $\ldots \ldots$

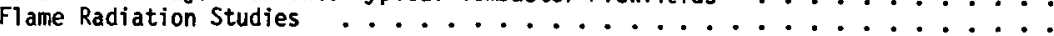

Turhine Heat Transfer

Mainstream Turbulence Influence on Flow in a Turning Duct - $A$

Mainstream Turbulence influence on Flow in a Turning Duct $-B \ldots$ $\star 2-D$ Heat Transfer without Film Cooling

*2-D Heat Transfer with Leading Edge Film cooling $\cdots$

2-D Heat Transfer with Downstream Film Cooling

* Measurement of $\mathrm{Bl}$ ade and Vane Heat Transfer Coefficient in a Turbine Rotor

*Assessment of 3-D Boundary Layer Code ................

*Cool ant Side Heat Transfer with Rotation $\ldots \ldots \ldots \ldots \ldots \ldots$

*Analytic flow and Heat Transfer

Effects of Turbulence on Heat Transfer

Tip Region Heat Transfer

Impingement cooling $\ldots \ldots \ldots \ldots$

Computation of Turbine Bi ade Heat Transfer $\ldots \ldots \ldots$

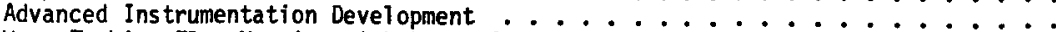

Warm Turbine Flow Mapping with Laser Anemometry $\ldots \ldots \ldots . . . . .$.

Real Engine-Type Turbine Aerothermal Testing $\ldots \ldots \ldots \ldots \ldots$

Structural Analysis

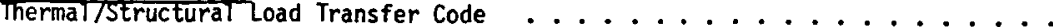

3-D Inelastic Analysis Methods - I . . . . . . . . . .

3-D Inelastic Analysis Methods - II $\ldots \ldots \ldots \ldots \ldots$

Component Specific Modeling $\ldots \ldots \ldots \ldots$

Liner Cyclic Life Determination $\ldots \ldots \ldots$

Structural Components Response Program

High Temperature Structures Research Laboratory $\ldots$

Constitutive Model Development $\ldots \ldots \ldots \ldots$

Constitutive Modeling for Isotropic Materials $-i \ldots \ldots$

Constitutive Modeling for Isotropic Materials - II $\ldots \ldots \ldots$

Theoretical Constitutive Models for Single Crystal Alloys ...................

Biaxial Constitutive Equation Development for Single Crystals and Directionaily

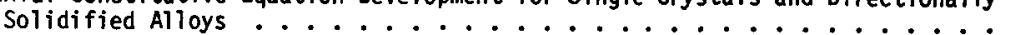

Fatigue and Fracture

Creep-Fatigue Life Prediction for Isotropic Materials

Elevated Temperature Crack Propagation

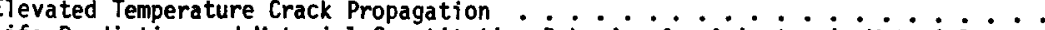

Life Prediction and Material Constitutive Behavior for Anisotropic Materiais : :

Analysis of Fatigue Crack Growth Mechanism ...

Vitalization of High Temperature Fatigue and Structures Laboratory $\ldots \ldots$

\section{Surface Protection}

Effects of Surface Chemistry on Hot Corrosion

Thermal Barrier coating Life Prediction - I

Thermal Barrier Coating Life Prediction - II $\ldots \ldots \ldots \ldots$

Thermal Barrier Coating Life Prediction - III $\ldots \ldots \ldots$

Airfoil Deposition Model

Mechanical Behavior of Thermal Barrier coatings $\ldots \ldots$

Coating Oxidation/Diffusion Prediction Coati

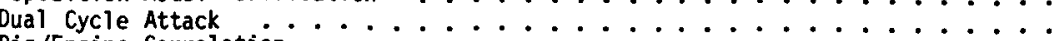

Rig/Engine Correlation $\ldots \ldots \ldots \ldots \ldots \ldots$

Burner Rig Modernization

Notes:

$$
\text { A, B II, III Activities in series }
$$

Contract (C), Grant (G), or NASA Organization (N) Number NAS3-23154 NAS3-24228

NAS3-23169

NAS3-23722

NAS3-23529

NAS3-26615

NAG3-501

2570

$2520 / 2530$

2510

NAS 3-23523

NAS3-23524

NAS3-23525

NAS3-24351

NAS3-24350

NAG3-596

NAS3-24350

NAS3-24350

NAS3 -24352

NAS3-22771

F33615-84-C-2427

NAS3-221 10

NAG3-549

2780

NAS3-23278

NAG3-617

NAS3-22761

NAS3-23695

NAS3-24619

NAS 3-23717

NAS3-2371 6

NAS3-23691

NAS3-24358

NAG3-522

NAG3-623

NSG3-075

NAG3-579

2640

2620

2640

NAS3-23272

NAS3-23697

NAS3-23698

NAS3-23687

5210

5210

5210

5270

NAS 3-23925

NAS3-23927

NAG3-511

NAG3-512

NAS 3-23288

NAS 3-23940

NAS 3-23939

NAG3-348

5220

NAS3-23926

NAS 3-23943

NAS3-23944

NAS3-23945

NAG3-201

NCC 3-27

5720

5140

5120

5120

5160 


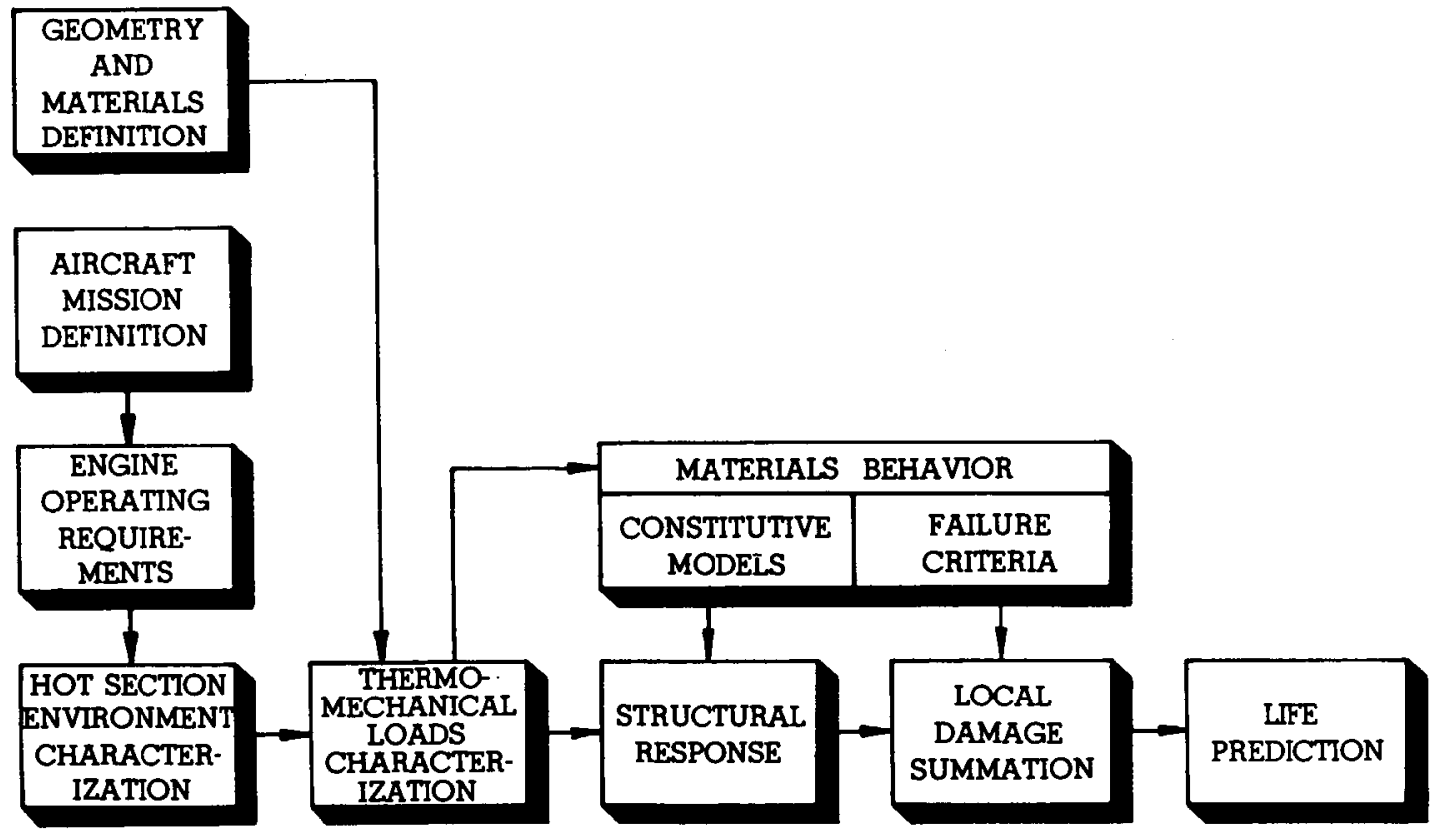

C0.85-17.14

Figure 1. - Integration of analytical models leads to life prediction of hot section parts.

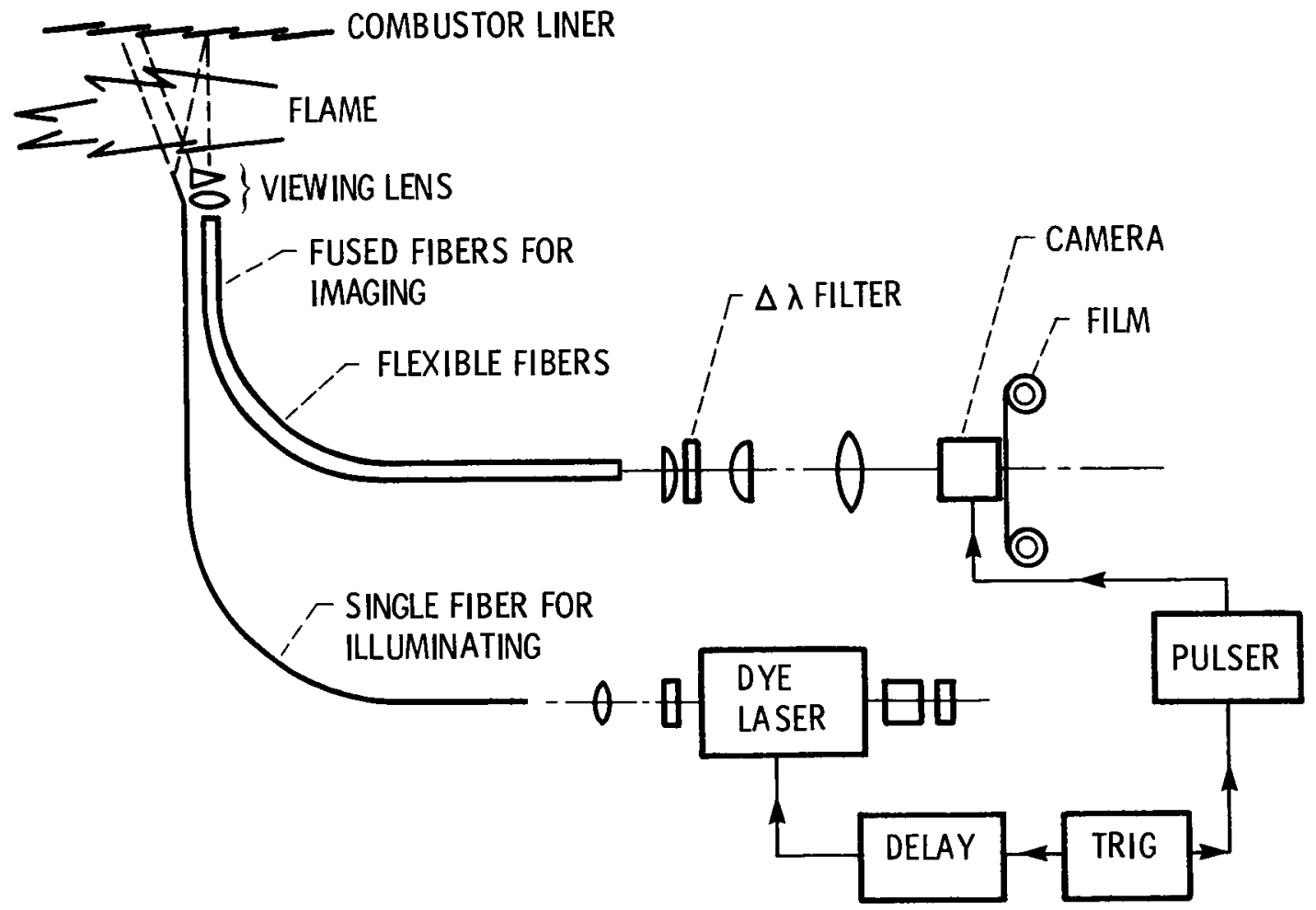

Figure 2-Combustor viewing system schematic (ref. 9). 


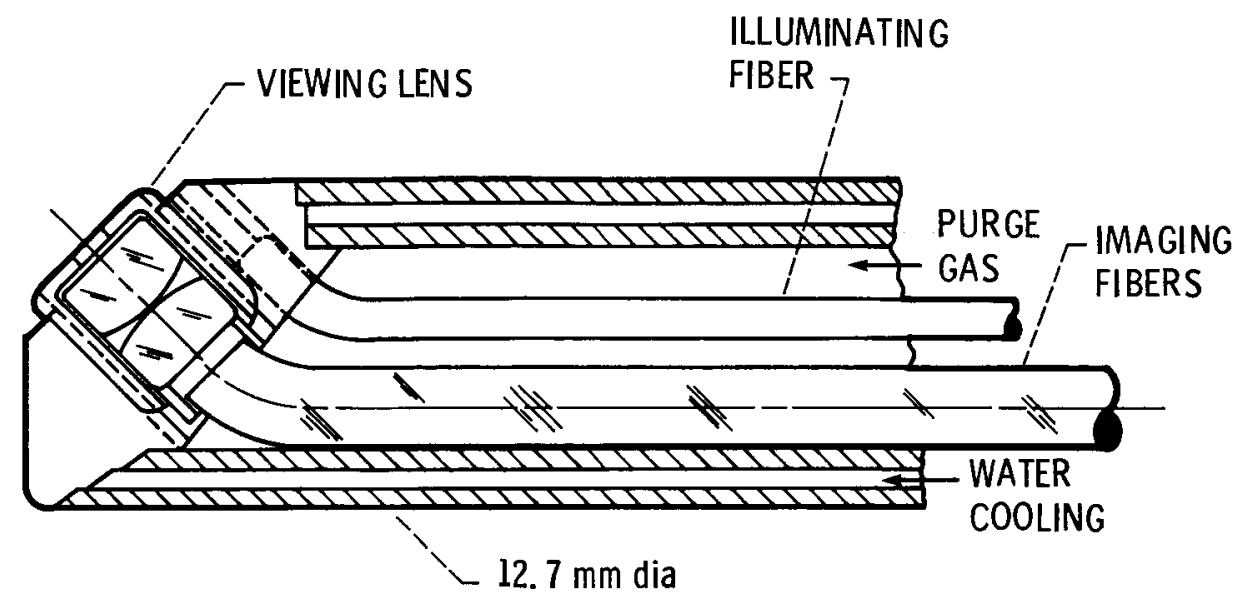

Figure 3. - Wide field of vien probe (ref。9).

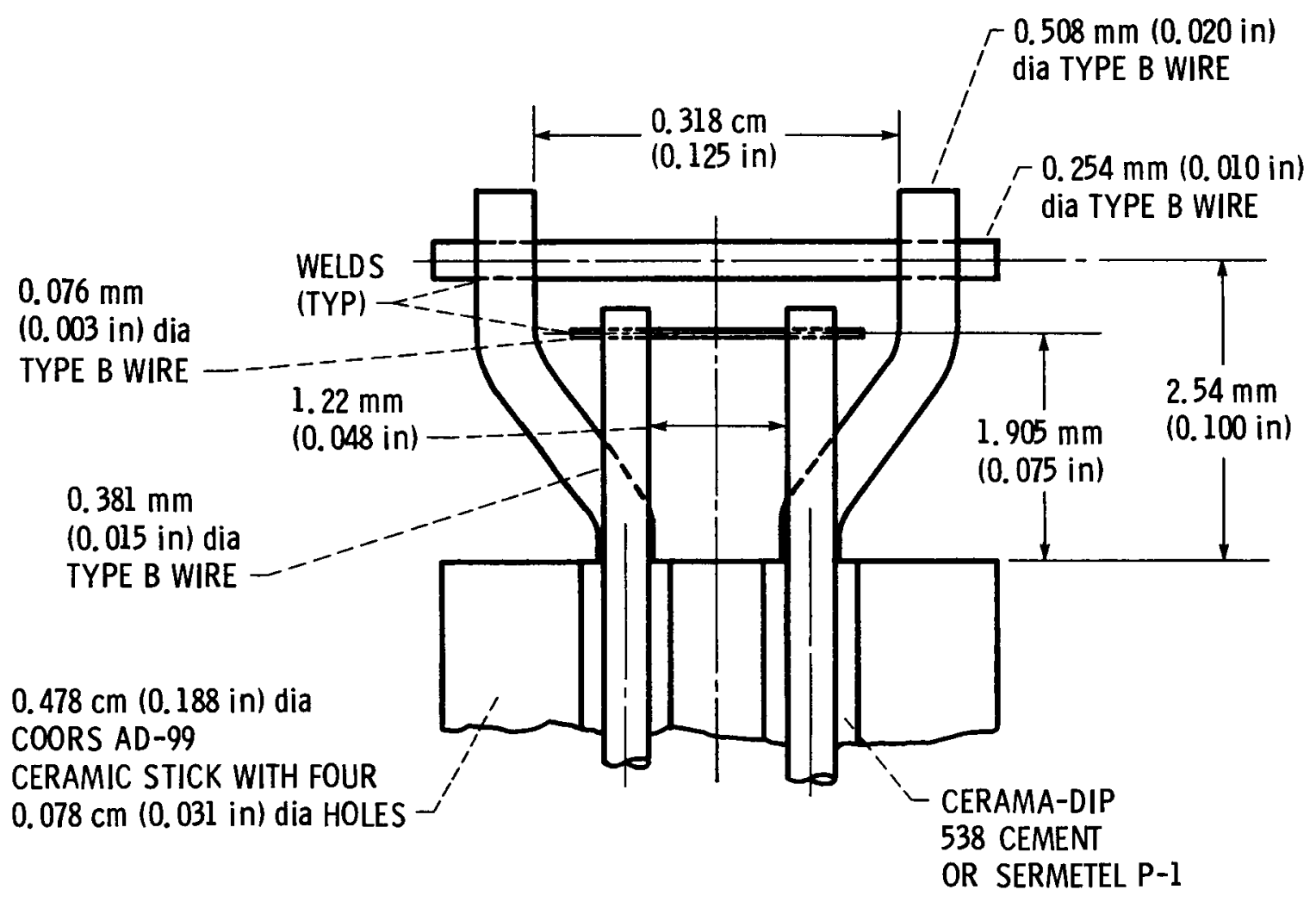

Figure 4. - Sensor tip geometry for dynamic gas temperature measurement system (ref. 5 and 10 ). 
$76 \mu \mathrm{m}$ (3 mil) T/C OUTPUT

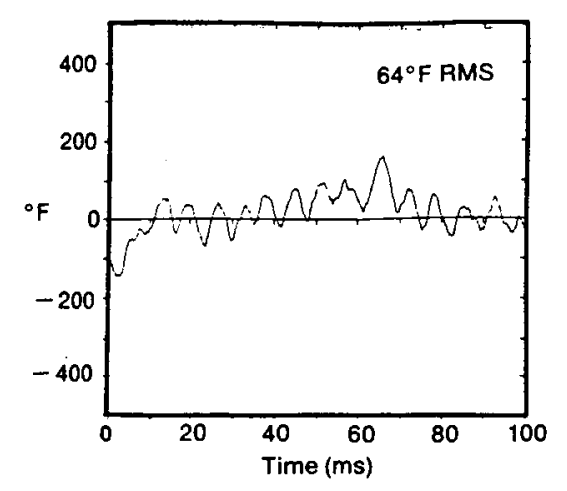

COMPENSATED $76 \mu \mathrm{m}$

(3 mil) T/C OUTPUT

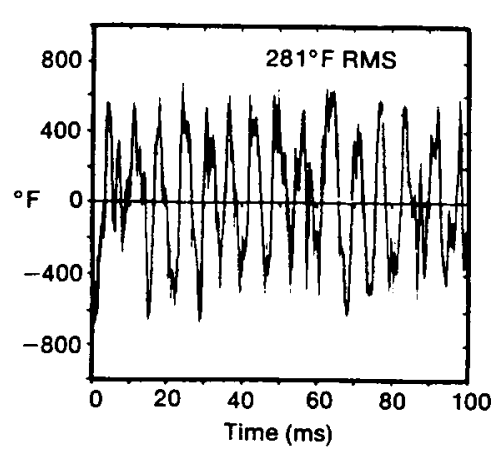

FIGURE 5. - COMBUSTOR EXIT TEMPERATURE FLUCTUATIONS FOR SUBSCALE COMBUSTOR TEST (REFS. 5 AND 10).

$76 \mu \mathrm{m}(3 \mathrm{mil}) \mathrm{T} / \mathrm{C}$ output

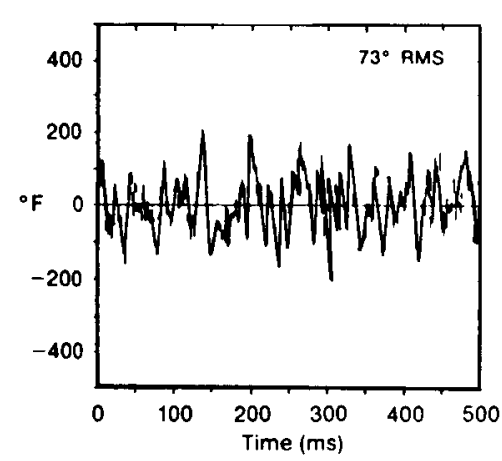

Compensated $76 \mu \mathrm{m}$ ( 3 mil) $\mathrm{T} / \mathrm{C}$ output WITH TIME SCALE EXPANDED

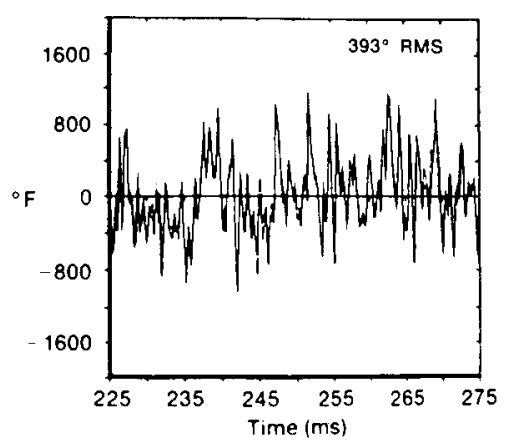

FIGURE 6. - COMBUSTOR EXIT TEMPERATURE FLUCTUATIONS FOR F-100 COMBUSTOR TEST (REFS. 5 AND 10). 

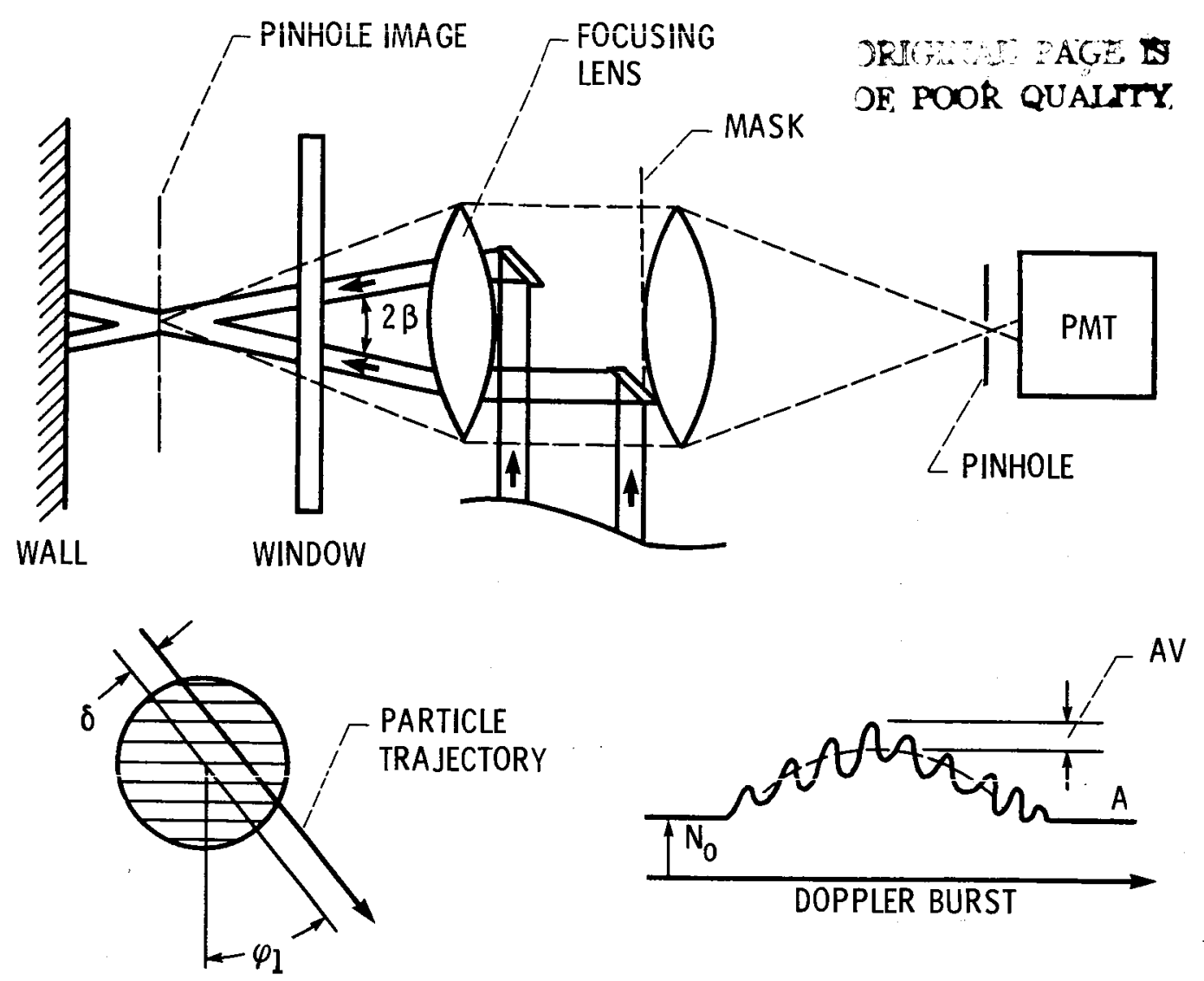

(A) FRINGE-TYPE LASER ANEMOMETER SCHEMATIC (REF. 6). FIGURE 7.

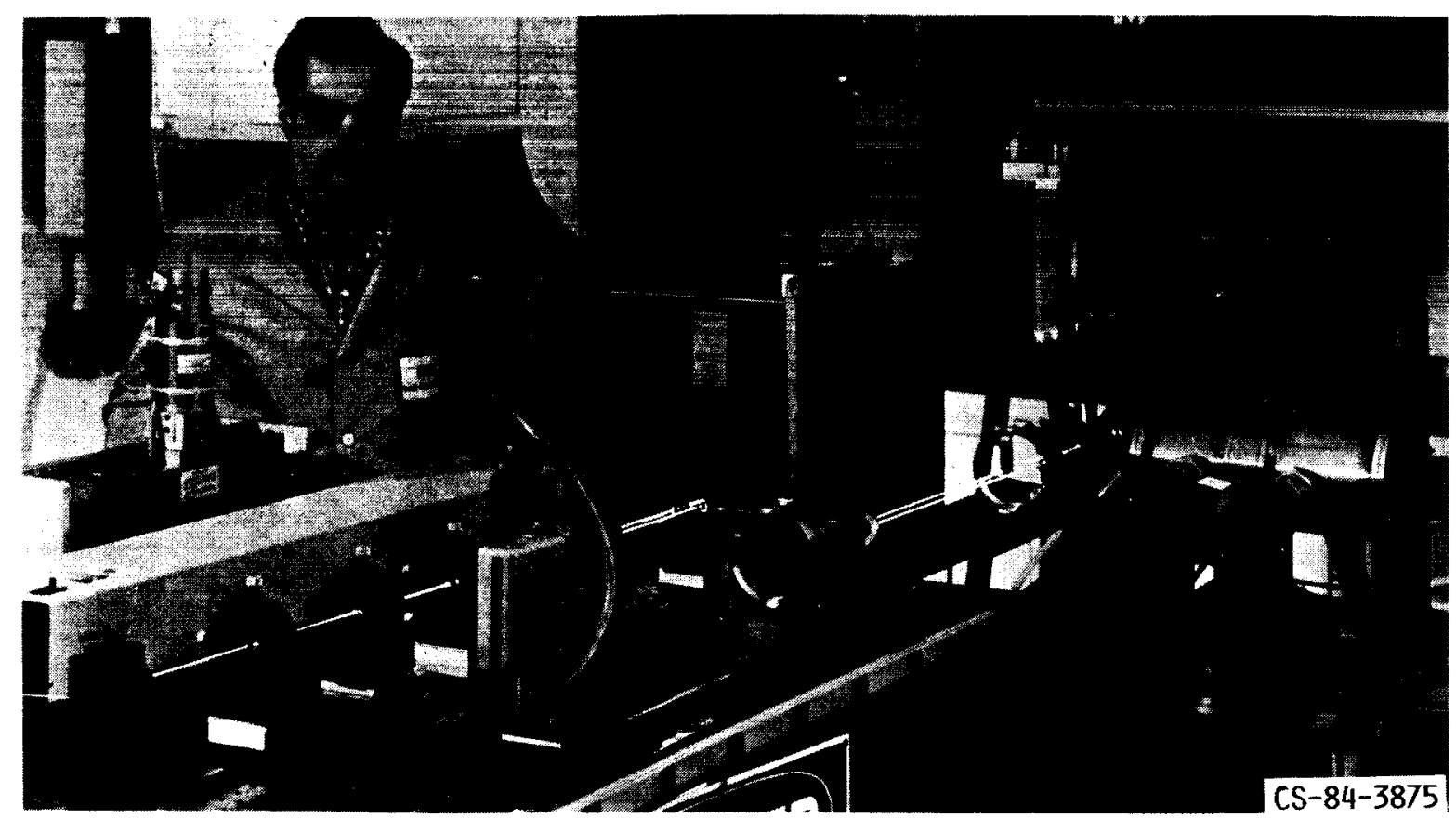

(B) LASER ANEMOMETER AND OPEN-JET COMBUSTOR (REF. 6). FIGURE 7. - CONCLUDED. 


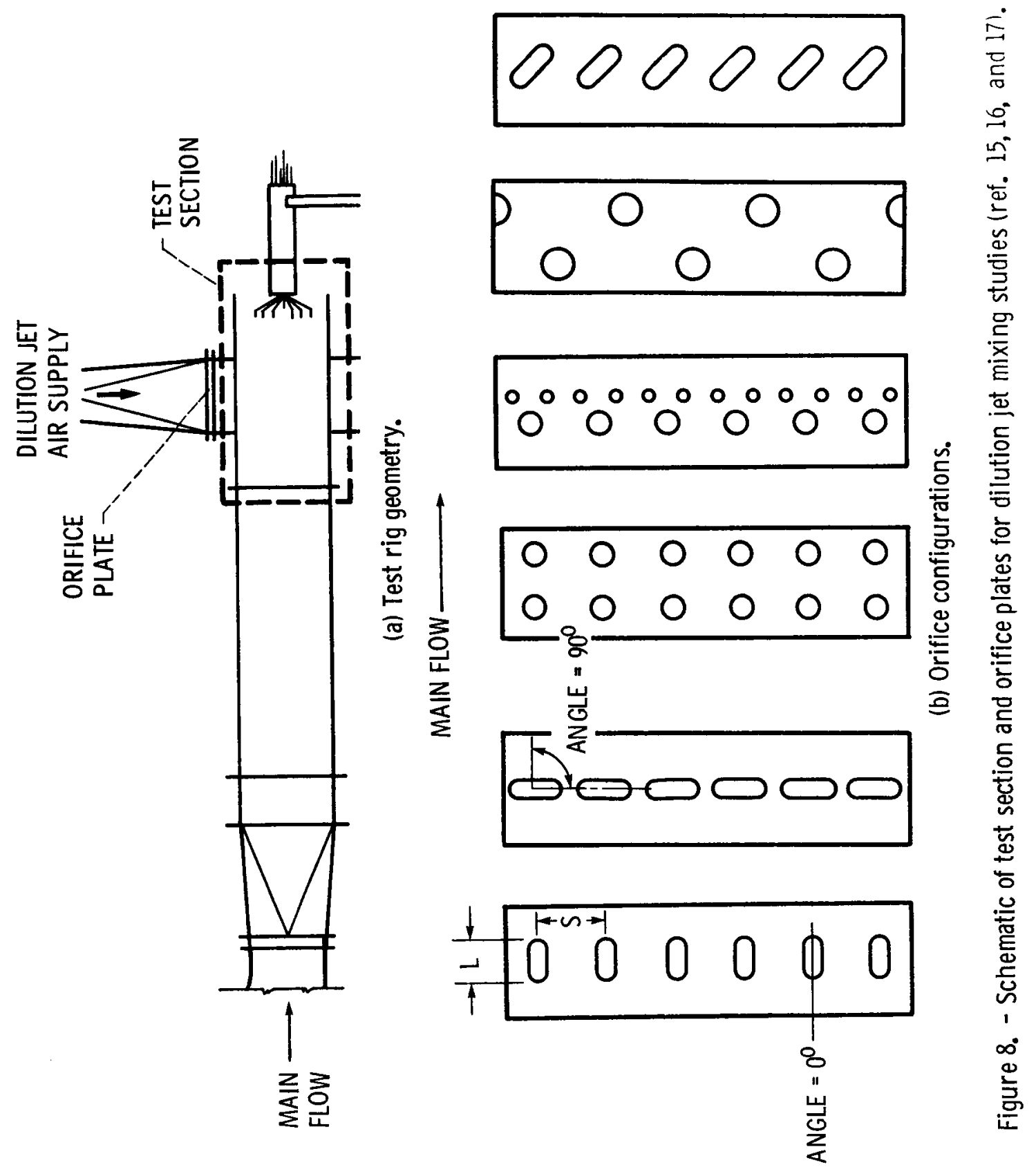



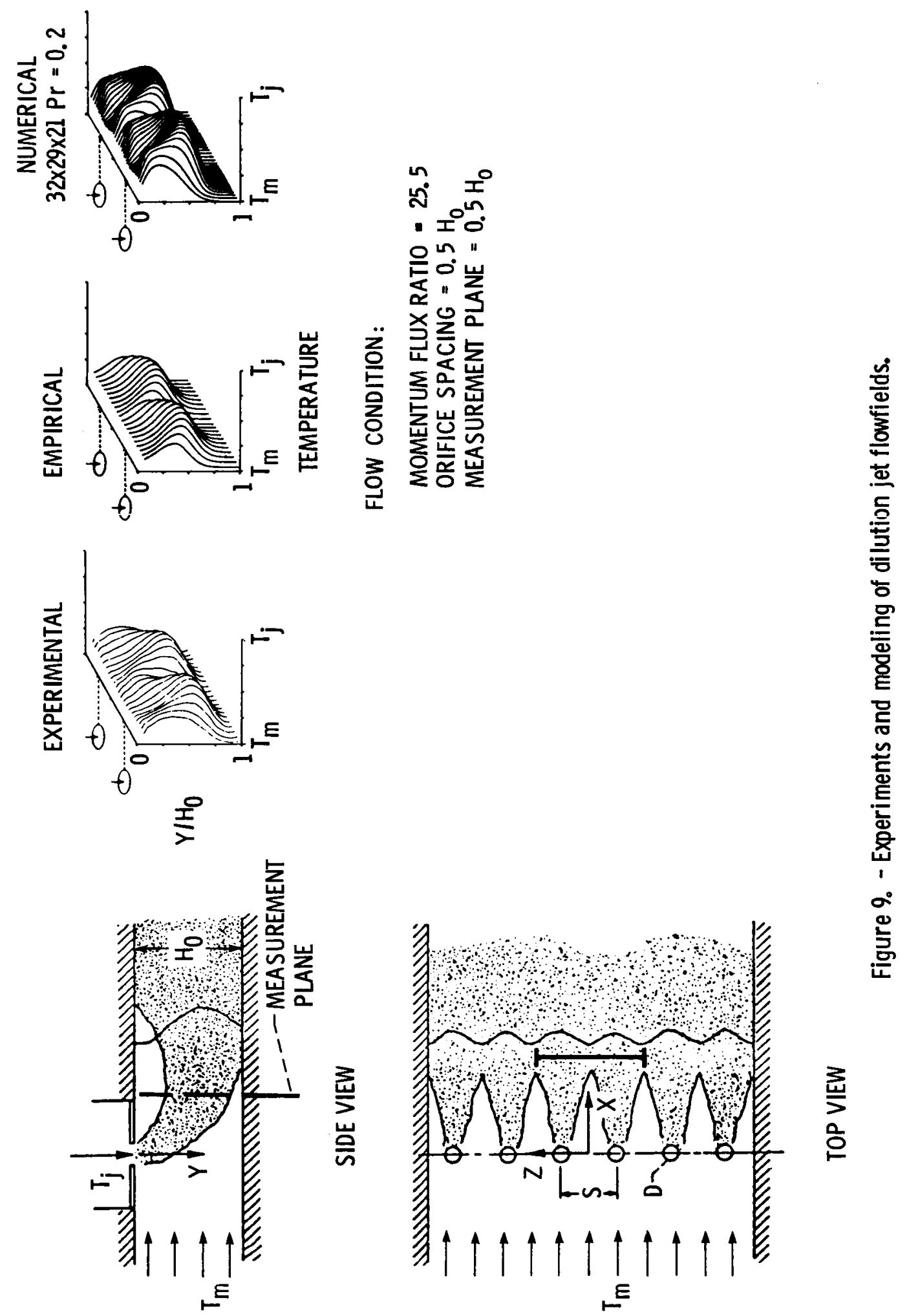

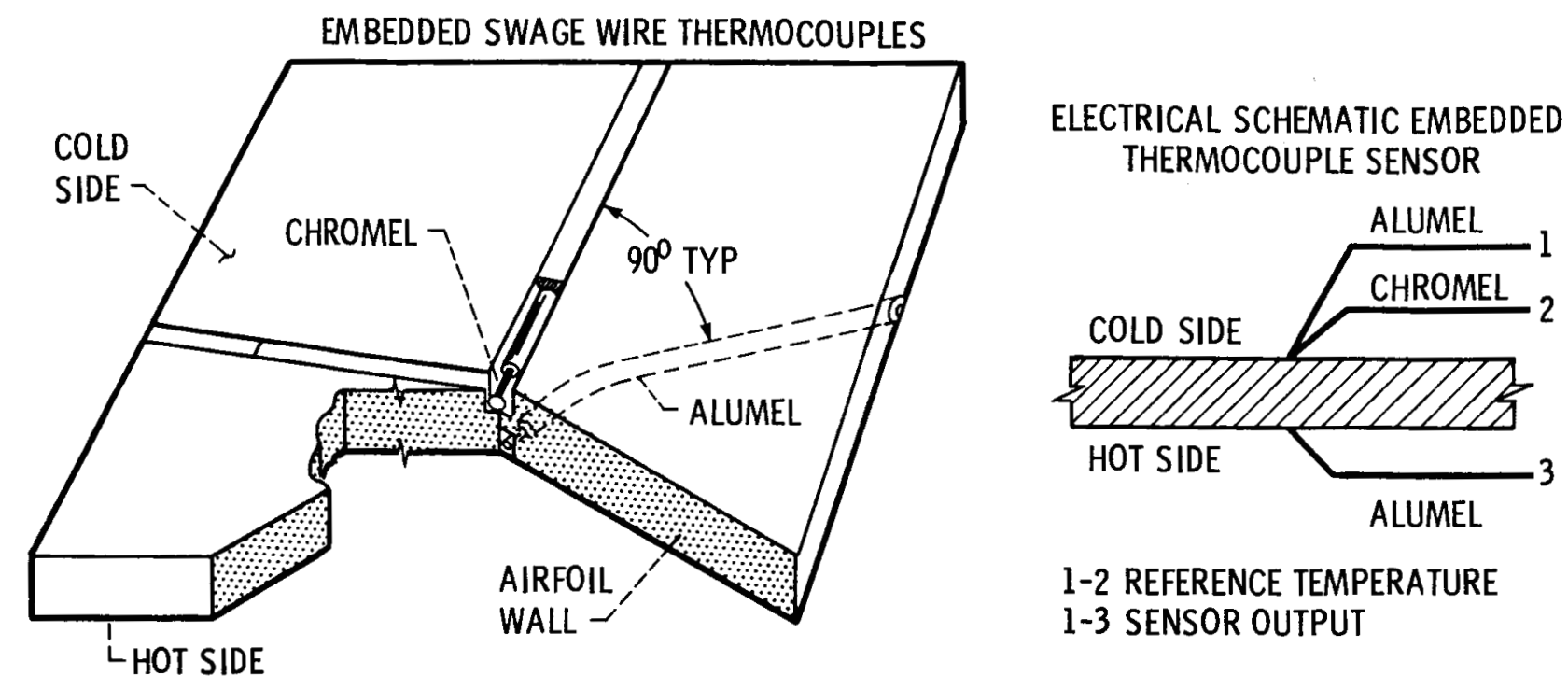

1-2 REFERENCE TEMPERATURE

1-3 SENSOR OUTPUT

(a) Schematic of embedded thermocouple sensor (ref. 5).

Figure 10.

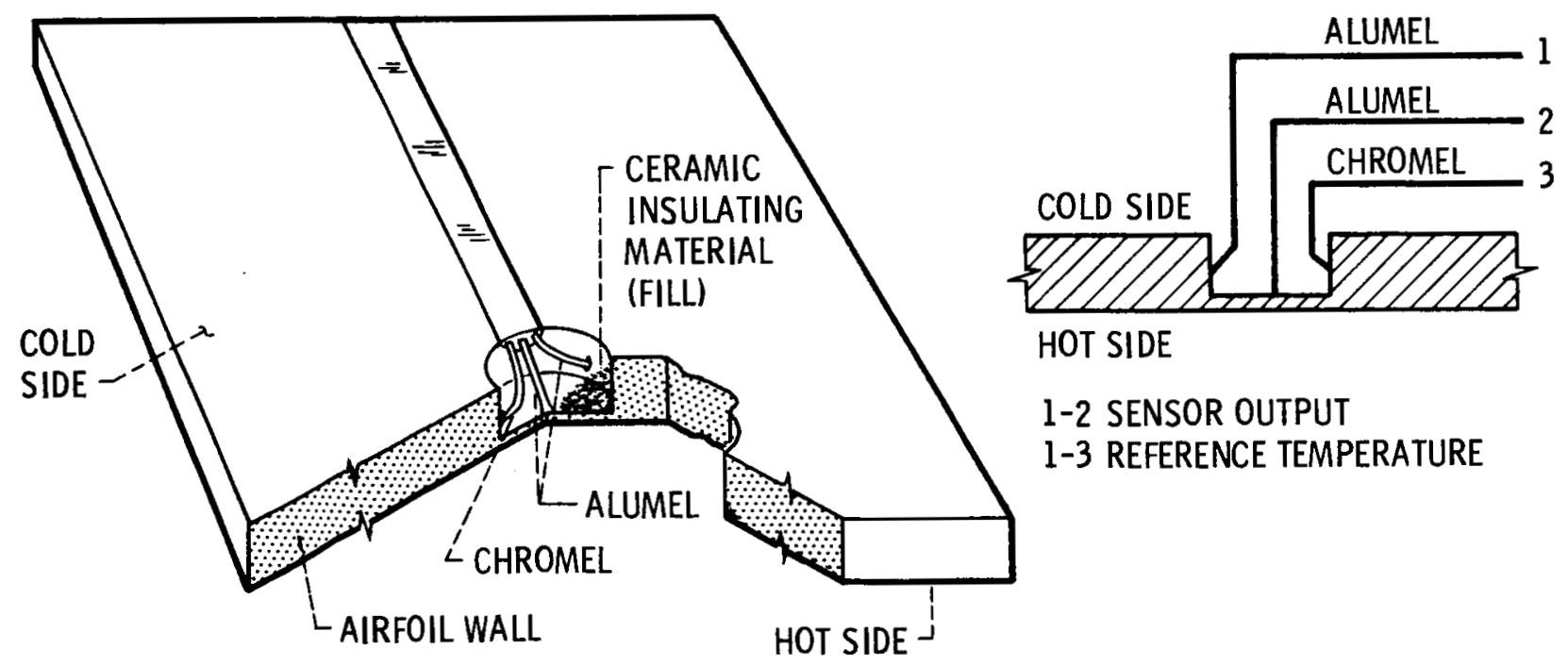

(b) Schematic of Gardon gage sensor (ref. 5).

Figure 10. - Concluded. 


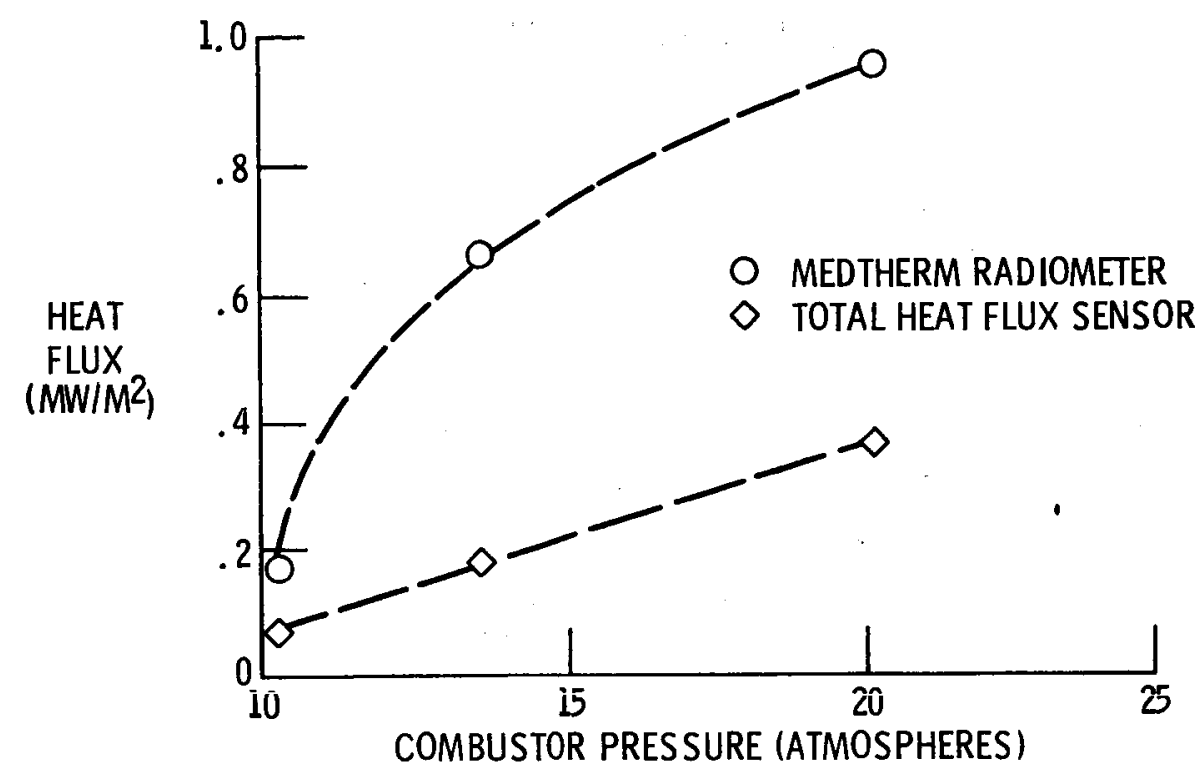

Figure 1l. - Typical test results from two types of heat flux sensors located in a combustor liner (ref. 20).
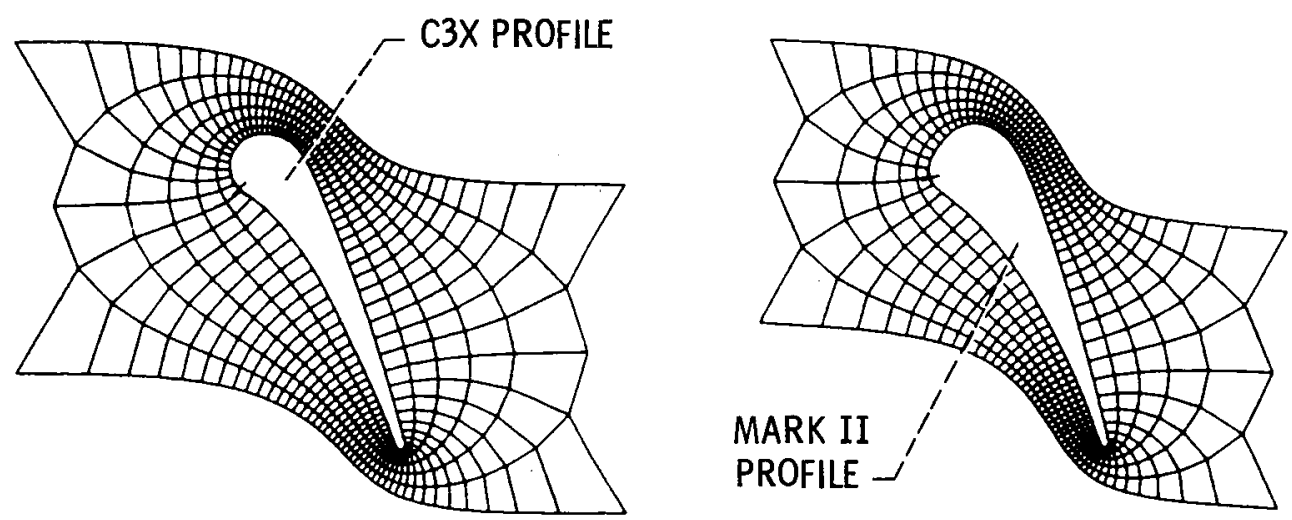

Figure 12. - Two airfoil profiles tested along with body-centered coordinate system grids generated as part of an inviscid blade-to-blade analysis (ref, 21). 
UNMODIFIED STAN5 RESULTS

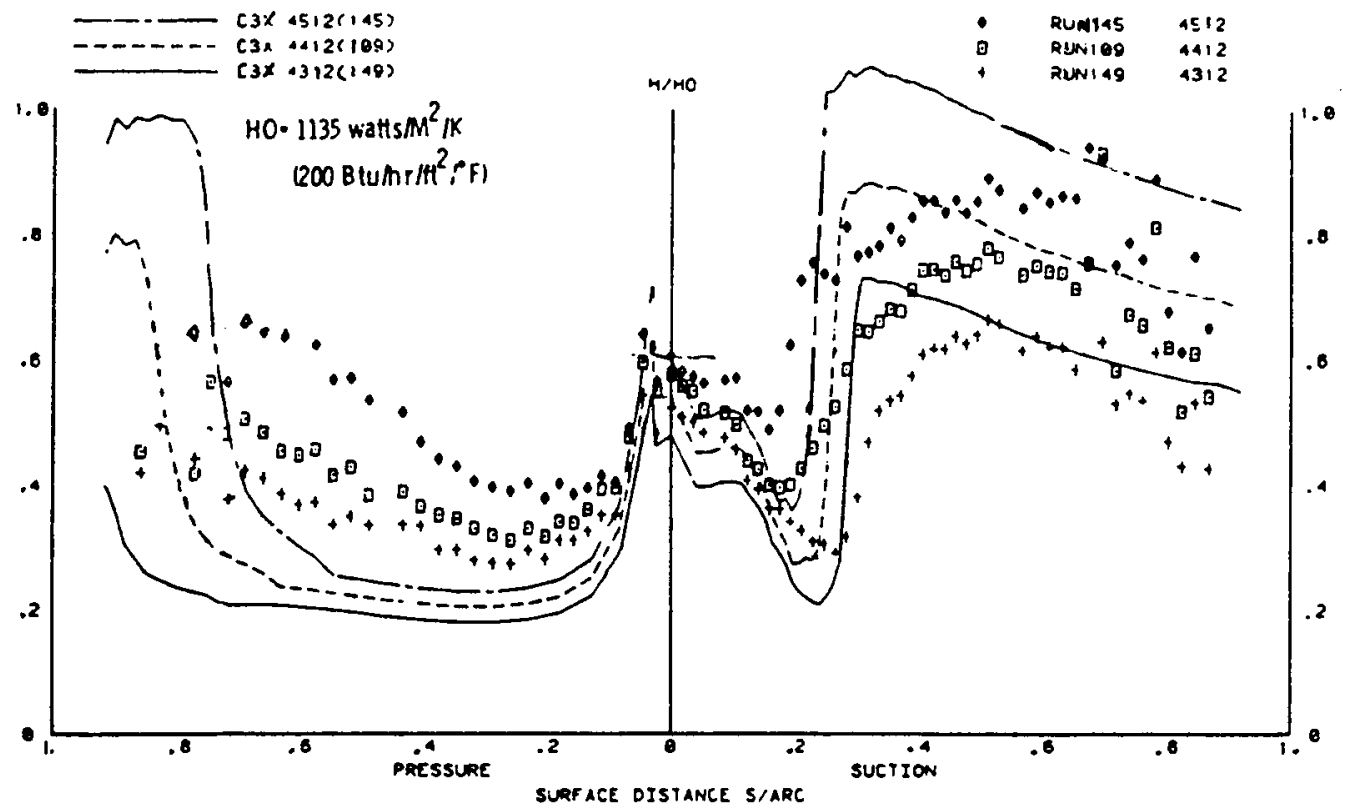

MODIFIED STAN5 RESULTS

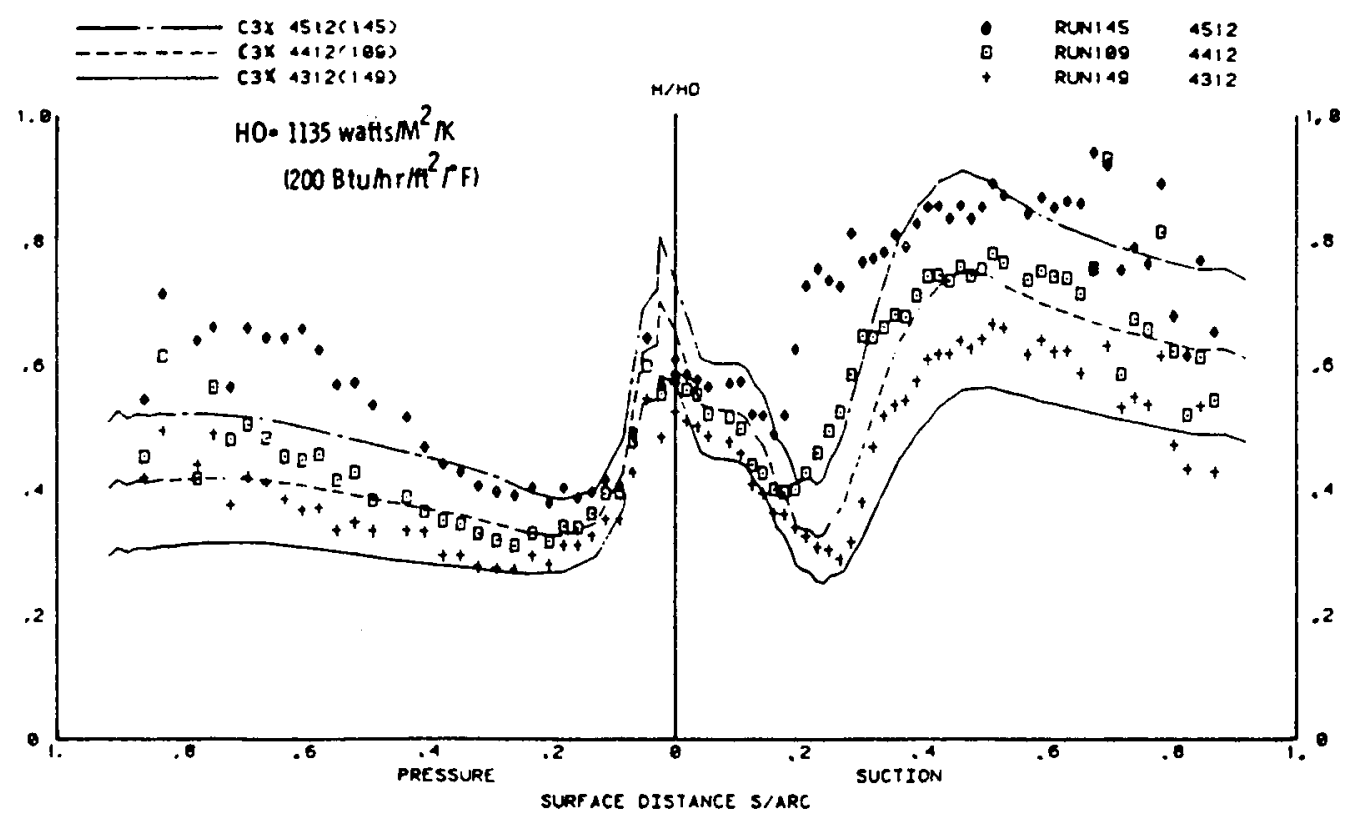

Figure 13. - STAN5 solutions compared with C3X airfoil experimental heat transfer coefficient data illu strating the effects of varying Reynolds number (ref. 21). 

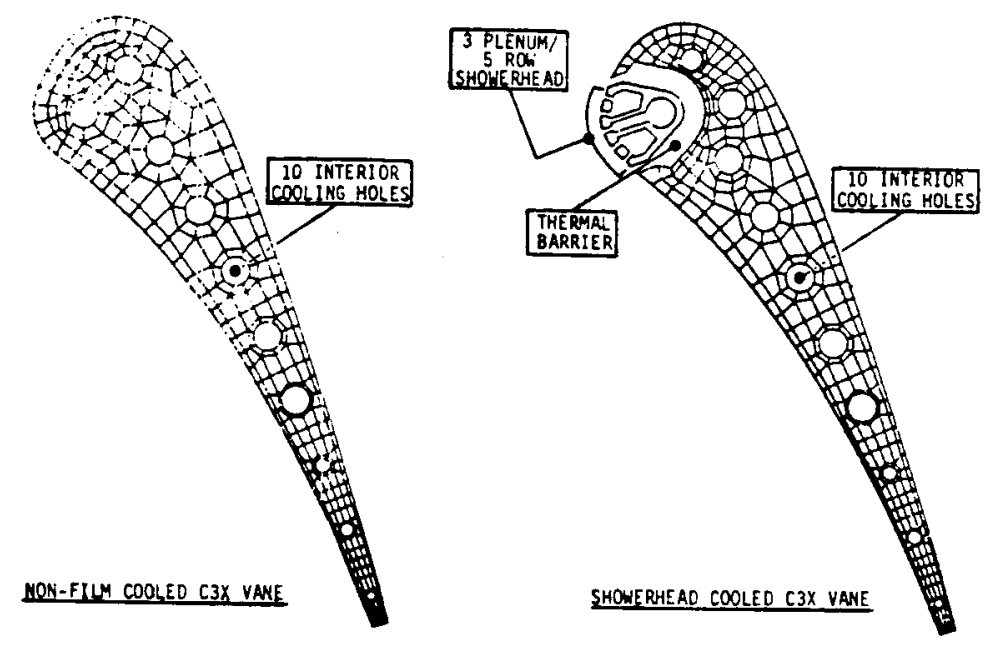

Figure 14 - Cross sectioñ of C3X vañes for head trannsfer experiments showing finite element grids (ref. 2 ).

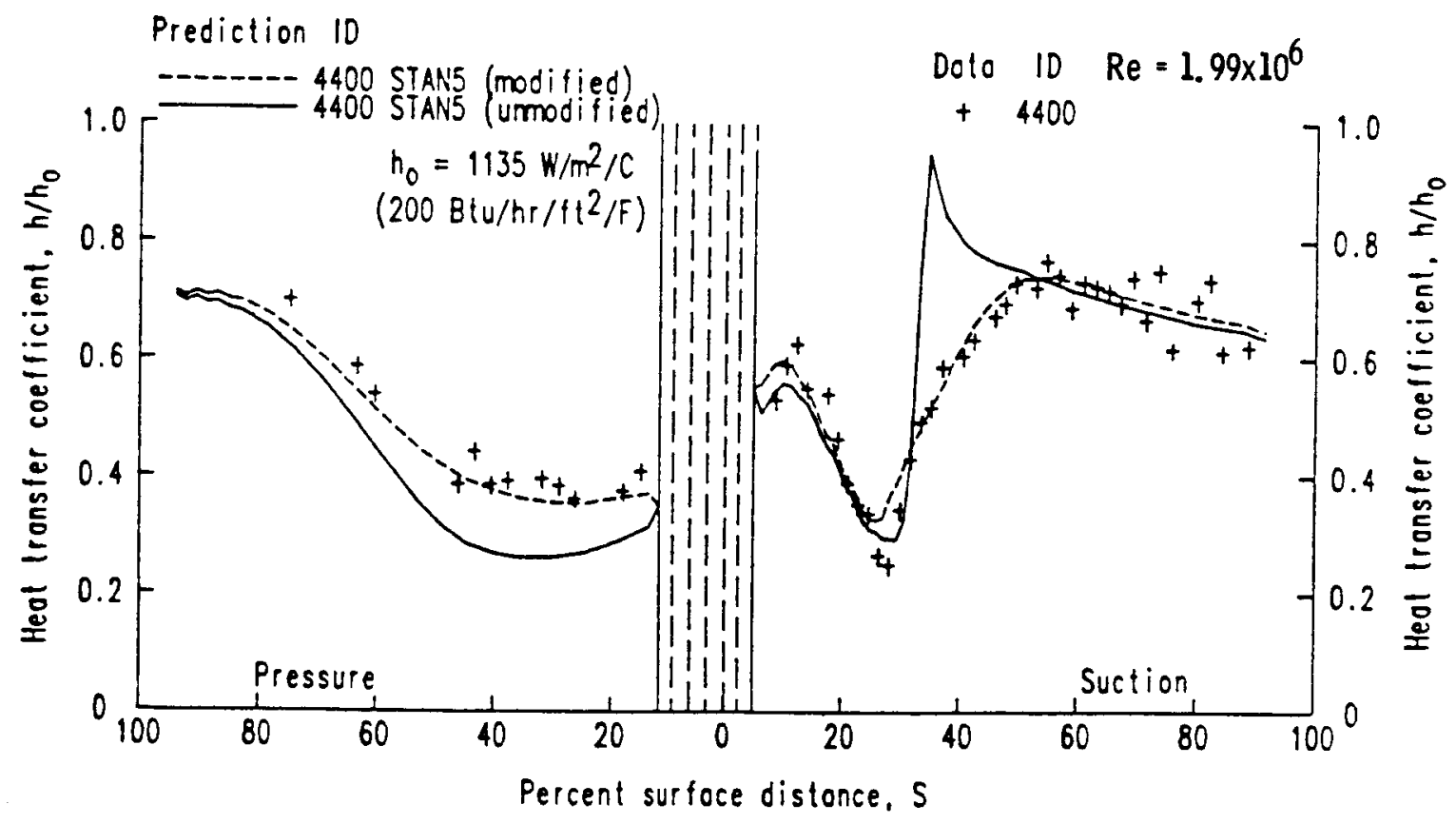

Figure 15. - Comparison of predicted suction and pressure surface heat transfer coefficient distributions using run 4400 STAN5 input data streams for showerhead cooled C3X vane (ref. 23). 


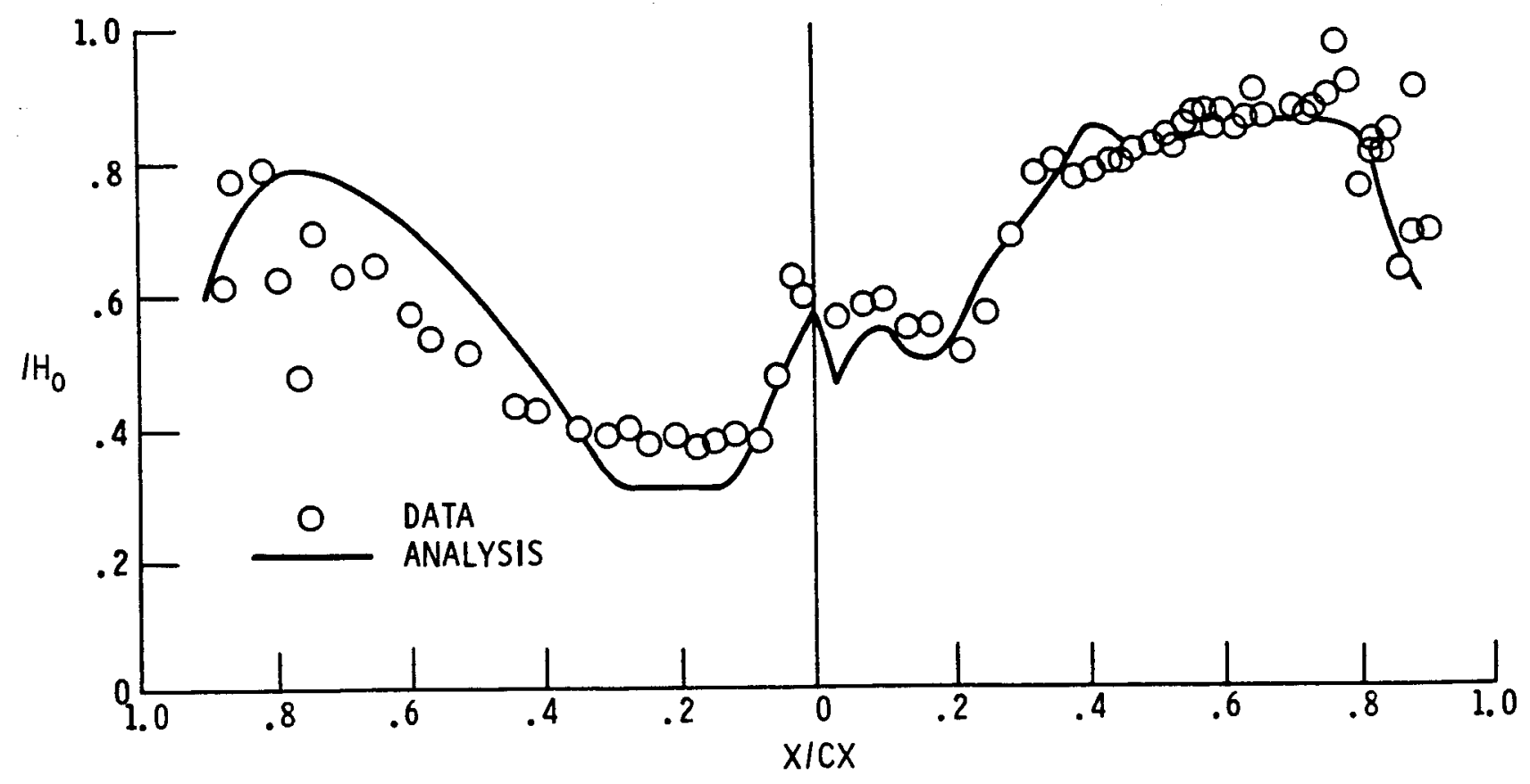

PRESSURE SIDE

SUCTION SIDE

FIGURE 16. - CALCULATION OF TURBINE AIRFOIL HEAT TRANSFER USING A THREE-DIMENSIONAL NAVIER-STOKES CODE (REF. 7).

$$
S t=\frac{\dot{q}_{w}}{P_{\infty} u_{\infty} c_{p}\left(t_{a}-t_{w}\right)}
$$

1.5 in. INLET BOUNDARY LAYER MEASURED

CALCULATED

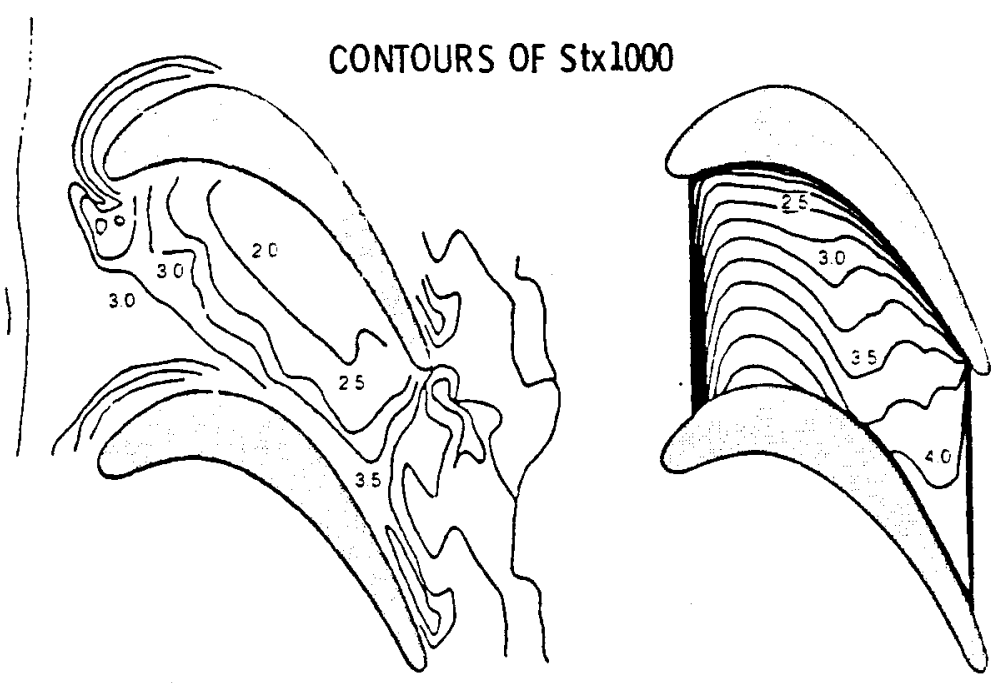

Figure 17. - Comparison of measured and calculated Stanton Number distributions for end wall surface (ref. 25). 


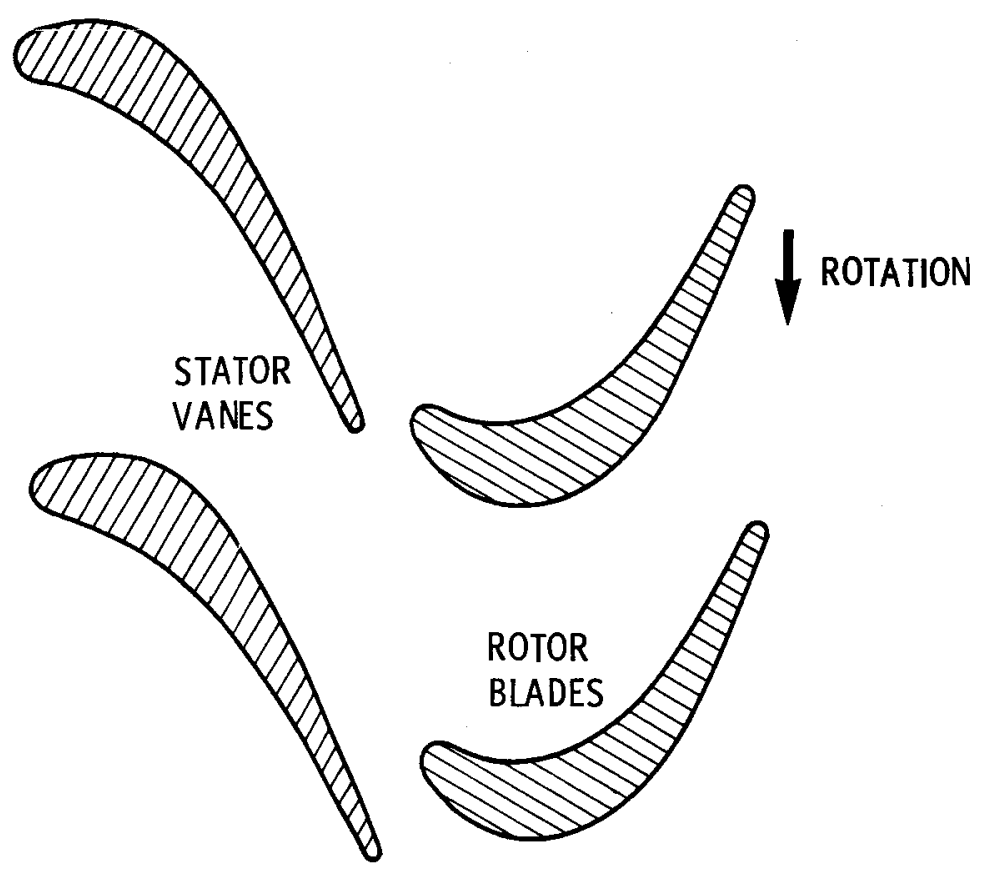

Figure 18. - Large low speed turbine stage (ref. 26).

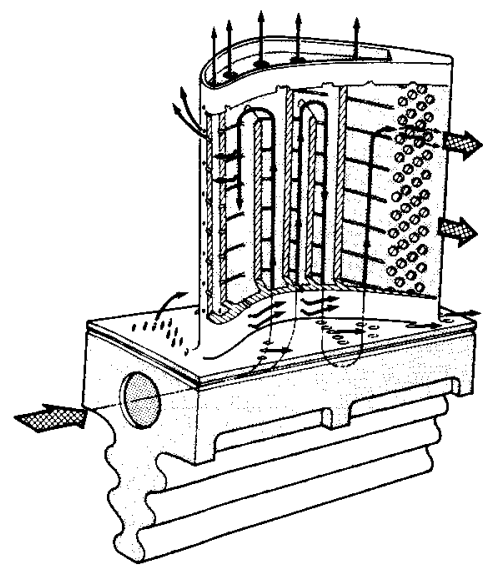

Figure 19. - A typical cooled aircraft gas turbine blade.

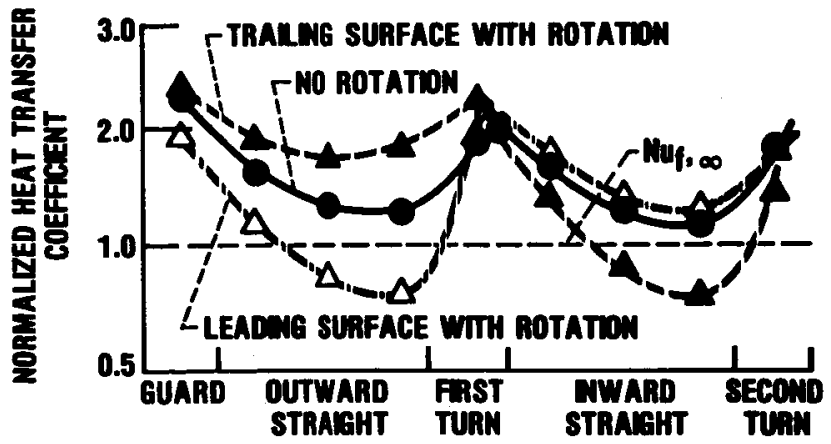

Figure 20. - Effect of rotation on coolant passage heat transfer. 


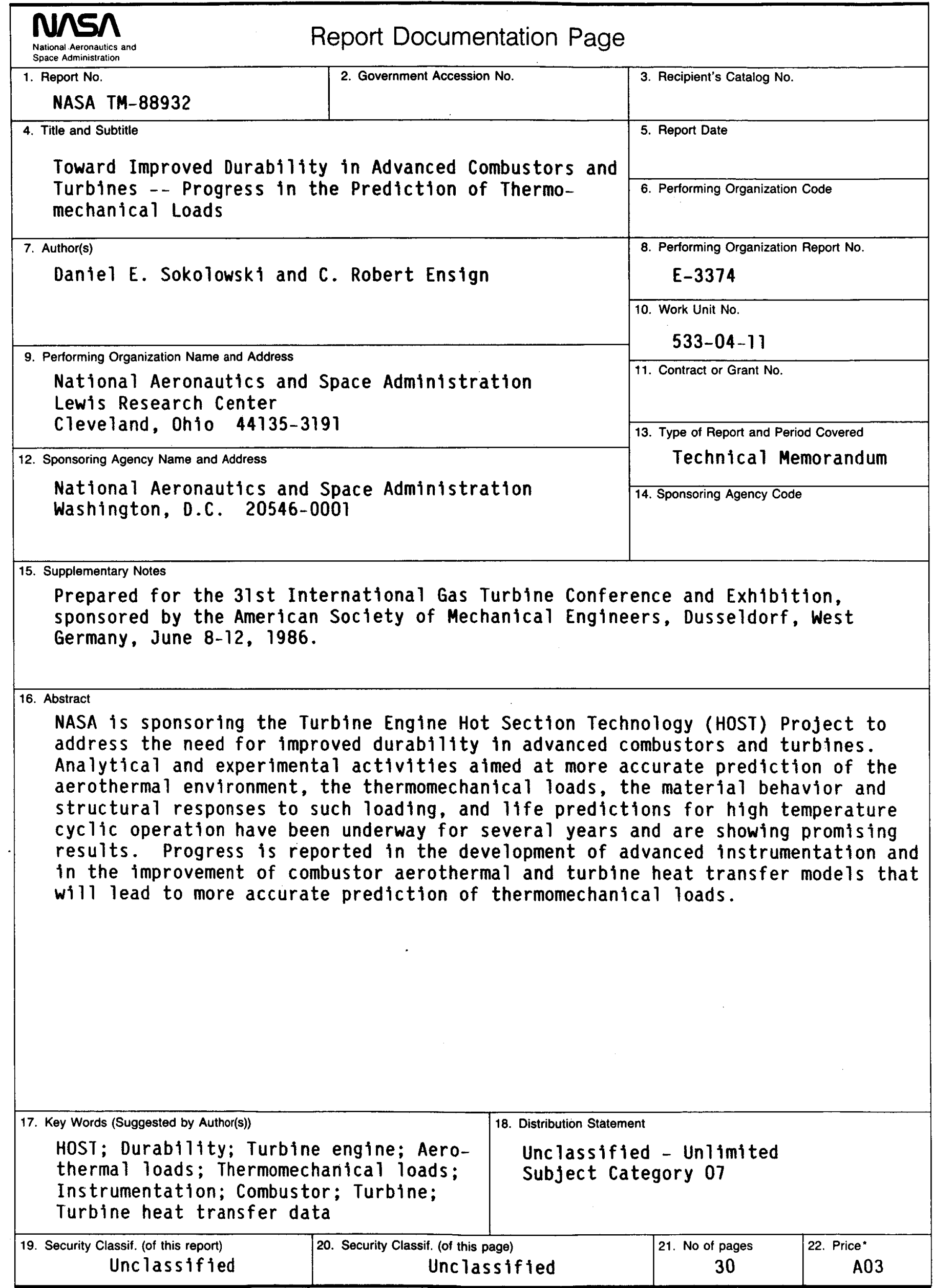

NASA FORM 1626 OCT $86 \quad$ *For sale by the National Technical Information Service, Springfield, Virginia 22161 